\title{
LAKE 2.0: a model for temperature, methane, carbon dioxide and oxygen dynamics in lakes
}

\author{
Victor Stepanenko $^{1}$, Ivan Mammarella ${ }^{2}$, Anne Ojala ${ }^{4,3}$, Heli Miettinen ${ }^{5}$, Vasily Lykosov ${ }^{6,1}$, and Timo Vesala ${ }^{2,3}$ \\ ${ }^{1}$ Lomonosov Moscow State University, GSP-1, 119234, Leninskie Gory, 1, bld. 4, Moscow, Russia \\ ${ }^{2}$ Department of Physics, P.O. Box 48, 00014, University of Helsinki, Helsinki, Finland \\ ${ }^{3}$ Department of Forest Sciences, P.O. Box 27, 00014, University of Helsinki, Helsinki, Finland \\ ${ }^{4}$ Department of Environmental Sciences, Niemenkatu 73, 15140 Lahti, University of Helsinki, Helsinki, Finland \\ ${ }^{5}$ Department of Environmental Sciences, P.O. Box 65, 00014, University of Helsinki, Helsinki, Finland \\ ${ }^{6}$ Institute of Numerical Mathematics, Russian Academy of Sciences, 119333, Gubkina, 8, Moscow, Russia \\ Correspondence to: Victor Stepanenko (stepanen@srcc.msu.ru)
}

Received: 30 November 2015 - Published in Geosci. Model Dev. Discuss.: 2 February 2016

Revised: 7 April 2016 - Accepted: 12 May 2016 - Published: 30 May 2016

\begin{abstract}
A one-dimensional (1-D) model for an enclosed basin (lake) is presented, which reproduces temperature, horizontal velocities, oxygen, carbon dioxide and methane in the basin. All prognostic variables are treated in a unified manner via a generic 1-D transport equation for horizontally averaged property. A water body interacts with underlying sediments. These sediments are represented by a set of vertical columns with heat, moisture and $\mathrm{CH}_{4}$ transport inside. The model is validated vs. a comprehensive observational data set gathered at Kuivajärvi Lake (southern Finland), demonstrating a fair agreement. The value of a key calibration constant, regulating the magnitude of methane production in sediments, corresponded well to that obtained from another two lakes. We demonstrated via surface seiche parameterization that the near-bottom turbulence induced by surface seiches is likely to significantly affect $\mathrm{CH}_{4}$ accumulation there. Furthermore, our results suggest that a gas transfer through thermocline under intense internal seiche motions is a bottleneck in quantifying greenhouse gas dynamics in dimictic lakes, which calls for further research.
\end{abstract}

\section{Introduction}

Freshwater lakes occupy $1.3-1.8 \%$, a comparatively small fraction, of land surface globally (Downing et al., 2006). However, regional thermodynamic and dynamic effects of lakes on weather and climate are important for most of
Canada, Finland, western Siberia and some other regions (Dutra et al., 2010; Martynov et al., 2012; Eerola et al., 2014). This motivated the inclusion of thermodynamic lake models into many numerical weather prediction (NWP) and climate models (Martynov et al., 2012; Dutra et al., 2010; Mironov et al., 2010; Subin et al., 2012; Rontu et al., 2012).

The other mode of freshwater body's impact on climate is that through the emissions of carbon dioxide $\left(\mathrm{CO}_{2}\right)$ and methane $\left(\mathrm{CH}_{4}\right)$ into the atmosphere (Tranvik et al., 2009). For instance, according to recent estimates (Bastviken et al., 2011), global $\mathrm{CH}_{4}$ flux from lakes offsets $25 \%$ of the estimated land carbon sink, implying that lakes are an important component of the global carbon cycle and climate system.

Concomitantly with growing awareness of lakes significance for current and future climate change, few attempts have been made to develop lake models, incorporating thermodynamics, turbulence and biogeochemistry in order to simulate $\mathrm{CH}_{4}$ and $\mathrm{CO}_{2}$ in natural water bodies (Stepanenko et al., 2011; Kessler et al., 2012; Tan et al., 2015). The ultimate goal of these developments is to study the response of lakes and their greenhouse gas emissions to future climate change (Tan and Zhuang, 2015b) and to assess the relevant feedbacks through implementation of biogeochemical lake models into the Earth system models. These lake models rely on well-established one-dimensional (1-D) thermodynamic and turbulence closure schemes, whereas biogeochemical modules proposed are still not convincingly constrained on the data from a sufficient number of lakes rep- 
resenting different regions. Moreover, physical schemes of lake models have to be reconsidered to match new requirements posed by biogeochemical modules, e.g. distinguishing between shallow and deep sediments, accurate treatment of hypolimnetic and thermocline mixing. In the LAKE model version 2.0 presented here, we address some of these questions and propose corresponding model improvements.

However, a number of problems arise concerning $\mathrm{CH}_{4}$ and $\mathrm{CO}_{2}$ modelling in lakes. First, a variety of biogeochemical processes involved in production and transformations of $\mathrm{CH}_{4}$ and $\mathrm{CO}_{2}$ are not well understood to an extent where rigorous mathematical description could be developed. For instance, methane production dependence on environmental factors has been tested in a bulk of studies (Borrel et al., 2011); however, to the best of our knowledge, only temperature dependence is quantified with high statistical confidence (e.g. (Yvon-Durocher et al., 2014)). Moreover, even a widely accepted statement that $\mathrm{CH}_{4}$ is produced exclusively in an anaerobic environment faces contradiction with some observational results (Damm et al., 2010), suggesting that there are $\mathrm{CH}_{4}$ production mechanisms that not comprehended so far even at a qualitative level. Second, lakes vary very much in climate, geological and biogeochemical environments, resulting in enormous variability in greenhouse gas status (Juutinen et al., 2009). This situation is complicated by high vertical and sometimes horizontal variability of gas concentrations in a given lake (Schilder et al., 2013; Blees et al., 2015). Third, when considering gas dynamics in lakes, new physical processes become crucial such as diffusion through the water surface (Donelan et al., 2002), vertical diffusion in metalimnion and hypolimnion, bubble interactions with sediments skeleton (Scandella et al., 2011), and others. Many of these have not been addressed enough so far in both theoretical and experimental studies.

The obstacles described above hinder development of a mathematical model from first principles. Therefore, any lake greenhouse gas model would inevitably contain a number of empirical constants to be calibrated on an extensive data set (Tan et al., 2015), which is a usual practice in, e.g. wetland $\mathrm{CH}_{4}$ models (Walter et al., 1996; Walter and Heimann, 2000; Wania et al., 2009; Melton et al., 2013). As the calibration is often performed via formal optimization algorithms, the errors caused by inconsistent or incorrect mathematical formulations in the model are compensated by incorrect (but "optimal") values of calibration parameters (right result from compensating errors).

This work aims to develop a lake model based on rigorous mathematical development feasible in the framework of a 1-D approach, applied for thermodynamic, hydrodynamic and biogeochemical prognostic variables in a unified manner. We avoid using procedures for formal optimization (calibration) of the model parameters, rather focusing on qualitative behaviour of the model and its sensitivity to selected uncertain processes and constants. The choice of processes and comprehensiveness of their mathematical representation is made to target the fair model performance in (i) a lake thermodynamic regime (temperature profile, energy fluxes), (ii) $\mathrm{O}_{2}, \mathrm{CO}_{2}$ and $\mathrm{CH}_{4}$ concentration distribution in the water column and fluxes to the atmosphere and (iii) vertical transport of water properties in order to ensure (i) and (ii). Vertical turbulent flux of dissolved gases through hypolimnion and metalimnion are of special concern in this work, since $\mathrm{CO}_{2}$ and $\mathrm{CH}_{4}$ mostly originate in the hypolimnion, while the major interest for the community is how much of these species evade to the atmosphere. The lake model developed here is based on the LAKE model, which has been continuously advanced during the last decade at Moscow State University (Stepanenko and Lykossov, 2005; Stepanenko et al., 2011) and was extensively validated in LakeMIP (Lake Model Intercomparison Project) experiments (Stepanenko et al., 2010, 2013, 2014) in terms of lake temperature and energy fluxes. The main development of LAKE 2.0 compared to LAKE includes a biogeochemical module, describing processes related to $\mathrm{O}_{2}, \mathrm{CO}_{2}$ and $\mathrm{CH}_{4}$ dynamics, multiple columns of sediments (facilitating heat and gas exchange between the water column and sediments at different depths) and surface seiche parameterization.

The model validation in terms of water temperature, $\mathrm{O}_{2}$, $\mathrm{CO}_{2}$ and $\mathrm{CH}_{4}$ was performed using a unique data set collected by the University of Helsinki at Kuivajärvi Lake, located near the SMEAR (Station for Measuring EcosystemAtmosphere Relations) II station in Hyytiälä, southern Finland (Hari and Kulmala, 2005).

The paper is organized as follows. Section 2 provides derivation of a generic 1-D equation that is then applied to temperature, horizontal velocities and dissolved gases. Section 3 introduces a reader to a complex of measurements conducted at Kuivajärvi Lake and a model set-up to simulate this lake. Furthermore, Sect. 4 presents comparison of model results to observed data in a reference model run. In Sect. 5, we analyse results of the reference experiment as well as of sensitivity experiments, elucidating the significance of vertical gas transport induced by surface and internal seiches. Conclusions are summarized in Sect. 6.

\section{The model overview}

LAKE model is a 1-D model solving horizontally averaged equations for heat, gases and momentum transport for an enclosed water body. For taking into account heat and gases exchange with sloping bottom, the scheme for water temperature and gas concentrations is coupled to sediment columns originating at the bottom at different depths (see Sect. 2.5). Below we provide the basics of a 1-D approach used and a general description for main groups of processes represented in the model. 


\subsection{The generic 1-D equation and vertical coordinate}

We commence the description of LAKE model with derivation of a generic 1-D lake modelling framework, implemented in the current version of the model with respect to all prognostic variables. We confine ourselves to a concise summary of that derivation, while the interested reader will find a rigorous mathematical development in Appendix A.

We start with the generic Reynolds-averaged advectiondiffusion equation for the quantity $f$, which might be one of the following horizontal velocity components: temperature, turbulent kinetic energy (TKE), TKE dissipation or gas concentration (hereafter using summation over repeated indices):

$c \frac{\partial f}{\partial t}=-c \frac{\partial u_{i} f}{\partial x_{i}}-\frac{\partial F_{i}}{\partial x_{i}}+R_{f}(f, \ldots)$,

assuming the mass conservation equation for incompressible fluid:

$\frac{\partial u_{i}}{\partial x_{i}}=0$,

where $u_{i}$ is the velocity component along $x_{i}$ Cartesian axis $\left(x_{3}=z\right.$ being an axis pointing along gravity and originating at a lake surface, $x_{1}=x, x_{2}=y$ the horizontal coordinates, $\left.u_{1}=u, u_{2}=v, u_{3}=w\right), F_{i}$ is the sum of non-advective (turbulent and non-turbulent) fluxes of a property $f$ along $x_{i}, c$ is an additional multiplier (specific heat in temperature equation, unity in other equations) and $R_{f}$ stands for the sum of sources and sinks of $f$. The horizontal averaging operator is then introduced as

$\bar{f}=\frac{\int_{A(z)} f(x, y, z) \mathrm{d} x \mathrm{~d} y}{A(z)}$,

with $A(z)$ denoting the area of horizontal cross section of a lake at depth $z$. After applying this operator to Eq. (1) and making use of appropriate simplifications (Appendix A) we get

$$
c \frac{\partial \bar{f}}{\partial t}=\quad \underbrace{-\frac{c}{A} \int_{\Gamma_{A(z)}} f\left(\boldsymbol{u}_{h} \cdot \boldsymbol{n}\right) \mathrm{d} l}
$$

I.Advection by inlets, outlets and groundwater discharge

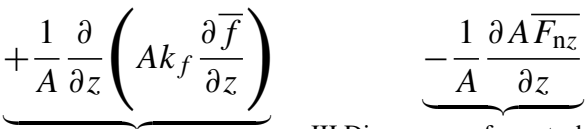

II.Turbulent diffusion/dissipation III.Divergence of non-turbulent flux

$$
\underbrace{+\frac{1}{A} \frac{\mathrm{d} A}{\mathrm{~d} z}\left(F_{\mathrm{n} z, \mathrm{~b}}(z)+F_{\mathrm{t} z, \mathrm{~b}}(z)\right)}
$$

IV.Contribution of the total vertical flux at the sloping bottom

$\underbrace{+R_{f}(\bar{f}, \ldots)}_{\text {V.Horizontally averaged sum of sinks and sources }}$, where we have decomposed the total vertical flux $F_{z}=F_{3}$ into turbulent flux, $F_{\mathrm{tz}}$, and a non-turbulent flux, $F_{\mathrm{n} z}, F_{z}=$ $F_{\mathrm{tz}}+F_{\mathrm{n} z} ; \boldsymbol{u}_{h}=\left(u_{1}, u_{2}\right) ; \boldsymbol{n}$ being an outer normal vector to the boundary $\Gamma_{A(z)}$ of the horizontal cross section $A(z) ; k_{f}$ the turbulent diffusivity (conductivity for temperature, viscosity for momentum) coefficient for variable $f$; and a subscript $b$ indicating a variable's value at the sloping bottom. The vertical fluxes of quantity $f$ at the lake's margins are $F_{\mathrm{t} z, \mathrm{~b}}$ and $F_{\mathrm{n} z, \mathrm{~b}}$, hereafter called marginal fluxes for brevity (marginal heat flux, marginal gas flux, marginal friction, etc.). For the horizontally mean turbulent flux we applied a first-order closure, $\overline{F_{\mathrm{t} z}}=-k_{f} \frac{\partial \bar{f}}{\partial z}$. The non-turbulent fluxes enter equations for temperature (shortwave radiation flux) and for gases' concentrations (bubble flux).

In Eq. (4), we neglected terms containing vertical velocity, $w$. There are two of them. First is $\partial(\bar{w} \bar{f}) / \partial z$ (Appendix A, Omstedt, 2011), which is justified to omit for lakes with slow water level change during the simulation period considered. Second is $\partial\left(\overline{w^{\prime} f^{\prime}}\right) / \partial z, a^{\prime}=a-\bar{a}, a=w, f$, representing the effect of vertical circulations of the scales larger than the Reynolds-averaging scale inherent to Eq. (1). The next paragraph considers the significance of this term.

The stratified enclosed water bodies under wind stress experience basin-scale circulations both above and below thermocline, the former induced by momentum flux from the atmosphere, and the latter by pressure gradient caused by lake surface and thermocline tilt. Frequently these motions oscillate in time, known as surface (barotropic) and internal (baroclinic) seiches (Wüest and Lorke, 2003). Under Earth's rotation, they transform to Kelvin and Poincare waves (Hutter et al., 2011). The practice of 1-D lake modelling, however, shows that under typical atmospheric forcing the top layer of a lake is almost always well mixed (the so-called mixed layer or epilimnion) during the ice-free period; therefore, any additional vertical mixing by basin-wide motion would not change vertical profiles there significantly. The well-mixed profiles below thermocline also may be produced involving simple seiche parameterization (Sect. 2.3), so that the explicit numerical treatment of closed vertical circulation would not alter vertical distribution of water properties there as well. The situation changes when the thermocline tilt becomes significant, i.e. when the thin interface between epilimnion and hypolimnion reaches the lake surface at its margins (Shintani et al., 2010). In this case it is the term $\partial\left(\overline{w^{\prime} f^{\prime}}\right) / \partial z$ that accounts for the eventual lake overturn, i.e. complete vertical homogenization of a water body. This process cannot be simulated by 1-D lake models explicitly, but may be diagnosed using Wedderburn (Shintani et al., 2010) and Lake numbers (Imberger and Patterson, 1989). Here, when applying the lake model for the lake under study, we will use Wed- 
derburn number time series to check the validity of dropping out the "vertical circulation term" 1 .

Equation (4) is a generalization of equations that include lake shape effects encountered in many 1-D models designed for lakes (Stefan and Fang, 1994; Goudsmit, 2002; Jönhk et al., 2008; Tan and Zhuang, 2015a) as well as for reservoirs (Zinoviev, 2014). In all 1-D lake models we are aware of, the term IV does not include shortwave radiation flux in the temperature equation and misses bubble flux of gases in equations for dissolved $\mathrm{CH}_{4}$ and $\mathrm{CO}_{2}$.

The form of Eq. (4) written using geometric vertical coordinate $z$ is not convenient for the case of significant rate of water level change. In order to tackle this case, a normalized vertical coordinate, $\xi=z / h(t)$, where $h$ is the maximal depth of a lake, has been introduced into equations of the model. Furthermore, the movement of the $z$ axis origin when the surface level changes, strictly speaking, results in an additional term to a generic Eq. (4). The above-mentioned leads to the following final form of Eq. (4):

$$
\begin{aligned}
c \frac{\partial \bar{f}}{\partial t} & =-\frac{c}{A} \int_{\Gamma_{A(\xi)}} f\left(\boldsymbol{u}_{h} \cdot \boldsymbol{n}\right) \mathrm{d} l+\frac{1}{A h^{2}} \frac{\partial}{\partial \xi}\left(A k_{f} \frac{\partial \bar{f}}{\partial \xi}\right) \\
& -\frac{1}{A h} \frac{\partial A \overline{F_{\mathrm{n} z}}}{\partial \xi}+\frac{1}{A h} \frac{\mathrm{d} A}{\mathrm{~d} \xi}\left[F_{\mathrm{n} z, \mathrm{~b}}(\xi)+F_{\mathrm{tz}, \mathrm{b}}(\xi)\right] \\
& +R_{f}(\bar{f}, \ldots)+\left[\frac{\xi}{h} \frac{\mathrm{d} h}{\mathrm{~d} t}-\frac{B_{\mathrm{s}}}{h}\right] \frac{\partial \bar{f}}{\partial \xi},
\end{aligned}
$$

where $B_{\mathrm{S}}$ signifies precipitation minus evaporation, i.e. the rate of $z$ axis origin motion, which is positive upwards. Although this is the form of Eq.(5), which is implemented in the LAKE model, it differs from Eq. (4) by metric terms only; therefore, for the sake of simplicity in subsequent text we will refer to Eq. (4). Moreover, in this work we will keep lake depth $h$ constant, which is realistic for the lake under study.

\subsection{Lake thermodynamics}

The water temperature in the model is driven by Eq. (4) with substitution $f \rightarrow T$, where $c=c_{\mathrm{w}} \rho_{\mathrm{w} 0}, c_{\mathrm{w}}$ is water specific heat, $\rho_{\mathrm{w} 0}$ - reference water density, $\overline{R_{f}}=0$ (no heat sources in the water besides radiation heating), $\overline{F_{\mathrm{n} z}(z)}=F_{\mathrm{n} z, \mathrm{~b}}(z)=$ $S_{\text {rad }}$ - shortwave radiation flux, which is positive downwards. The latter equality means that we assumed shortwave radiation flux to be horizontally homogeneous at all depths. This is commonly used approximation, as getting data of the spatial distribution of turbidity in a lake requires special measurements. Heat conductance is a sum of molecular and turbulent coefficients, $k_{T}=\lambda_{\mathrm{m}}+\lambda_{\mathrm{t}}$, where $\lambda_{\mathrm{t}}=c_{\mathrm{w}} \rho_{\mathrm{w} 0} \nu_{T}$ ( $v_{T}$ the tur-

\footnotetext{
${ }^{1}$ Other possible mechanisms for basin-scale circulations include density currents along sloping bottom (Chubarenko, 2010; Kirillin et al., 2015) during transitional seasons and the ice period.
}

bulent heat transfer coefficient, $\mathrm{m}^{2} \mathrm{~s}^{-1}$ ) is computed from the $k-\epsilon$ model (see Sect. 2.4).

Shortwave radiation flux, $S$, is treated as consisting of near-infrared fraction and the rest energy (mostly visible radiation). The near-infrared part is consumed completely at the surface, whereas the visible fraction is partially reflected according to water albedo, and its remainder is attenuated with depth according to the widely used Beer-Lambert law with an extinction coefficient specific for the lake under study (see Sect. 3.2).

To solve Eq. (4) for temperature one needs to specify top and bottom boundary conditions as well as a method for the calculation of marginal heat flux, $F_{\mathrm{tz}, \mathrm{b}}(z)$, at each depth $z$. The top boundary condition is a well-established heat balance equation, involving net radiation and a scheme for turbulent heat fluxes in a surface atmospheric layer based on Monin-Obukhov similarity theory (Paulson, 1970; Businger et al., 1971; Beljaars and Holtslag, 1991). The way of coupling the water column to bottom sediments through a lower boundary condition and marginal heat flux is less straightforward. When the heat transfer in bottom sediments is solved by a diffusion-type equation, there are two options for imposing boundary conditions at the "water-sediments" interface:

- continuity of both heat flux and temperature at the interface;

- continuity of heat flux across the interface and a method for heat flux calculation, relating it to an in-water temperature gradient, e.g. through logarithmic profile formulae.

The same options hold for $\mathrm{CH}_{4}$ concentration, as diffusion-type equations are solved in the water column and in each sediment column for this property as well (see Sects. 2.6.1 and 2.6.2). We found that the first option provides reasonable results for temperature and especially for $\mathrm{CH}_{4}$ concentrations (see below in the paper), whereas the second one needs calibration of parameters entering the flux-gradient relationship in the bottom boundary layer. The marginal heat flux is calculated using the same temperature $\left(\mathrm{CH}_{4}\right.$ concentration) and flux continuity condition, which is facilitated by the solution of vertical heat $\left(\mathrm{CH}_{4}\right)$ transfer in sediments below sloping bottom (see details in Sect. 2.5).

The model also includes multilayer snow and ice modules (Stepanenko and Lykossov, 2005; Stepanenko et al., 2011) that are not used in this study.

\subsection{Lake hydrodynamics}

Applying the form of Eq. (4) to horizontal momentum equations is straightforward with $F_{\mathrm{n} z}=0, c=1$ and $R_{f}$ representing the Coriolis force and horizontal pressure gradient. The Coriolis force has to be included in the momentum equations for lakes with horizontal size that exceeds the internal Rossby deformation radius (Patterson et al., 1984), which we 

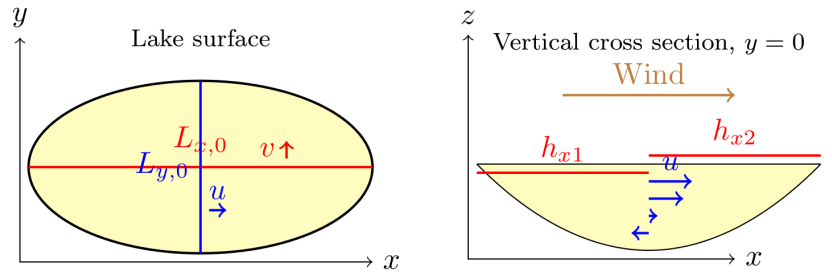

Figure 1. The sketch describing variables used in surface seiche parameterization. Lake surface is approximated by an ellipse, whose axes are $L_{x 0}$ and $L_{y 0}$. Variable $h_{x 1}$ is an average surface height of the left-half domain of lake, $h_{x 2}$ is that of a right-half domain; $h_{y 1}$ and $h_{y 2}$ are defined analogously for the lower and upper halves.

will check below when validating the model for the lake under study.

The term $F_{\mathrm{t} z, \mathrm{~b}}(z) A^{-1} \mathrm{~d} A / \mathrm{d} z$ repeats marginal friction in the case of momentum equations. This term can be parameterized as quadratic in velocity with a tunable proportionality coefficient (Jöhnk, 2001). Instead, we apply logarithmic layer friction with effective bottom roughness length, $z_{0 \mathrm{~b} \text {,eff }}$. The characteristic "effective" with respect to $z_{0 \mathrm{~b} \text {,eff accounts }}$ for the fact that while calculating bottom friction we use horizontally averaged velocity components $\bar{u}, \bar{v}$ instead of the velocity components' values in the logarithmic layer adjacent to the bottom. As there are no theoretical hints to how $z_{0 \mathrm{~b} \text {,eff }}$ relates to the "true" bottom roughness, $z_{0 \mathrm{~b}}$, it may be used as a tunable parameter. However, our modelling results show

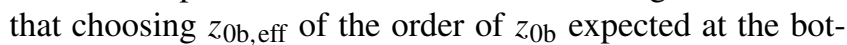
tom eventually provides reasonable results in terms of vertical mixing of water properties.

The more interesting story comes with parameterization of the horizontal pressure gradient. We represent it at any depth $z$ as

$-\frac{1}{\rho_{\mathrm{w} 0}} \frac{\partial p}{\partial x_{i}}=-g \frac{\partial h_{\mathrm{s}}}{\partial x_{i}}, i=1,2$

( $h_{\mathrm{s}}$ is the lake surface deviation from horizontal) implying that we have used a hydrostatic equation with constant density, $\rho_{\mathrm{w} 0}$. This is a barotropic approximation since we neglected buoyancy in the hydrostatic equilibrium ${ }^{2}$. It is the simplest way to account for horizontal pressure differences still being capable of inducing significant mixing below the thermocline (see below).

To estimate terms in Eq. (6) in a 1-D model, we modify the scheme proposed originally by Svensson (1978); Goudsmit (2002). Figure 1 provides a concept of the scheme. The parameterization takes the form

\footnotetext{
${ }^{2}$ The only place in the model where buoyancy expressed by temperature fluctuations is taken into account is the $k-\epsilon$ closure, Sect. 2.4. It formally adds baroclinicity to the model, however, only in subgrid-scale stress/fluxes.
}

$g \frac{\overline{\partial h_{\mathrm{s}}}}{\partial x} \approx \frac{g \pi^{2}}{4} \frac{h_{\mathrm{s}, x 2}-h_{\mathrm{s}, x 1}}{L_{x, 0}}$,
$g \frac{\overline{\partial h_{\mathrm{s}}}}{\partial y} \approx \frac{g \pi^{2}}{4} \frac{h_{\mathrm{s}, y 2}-h_{\mathrm{s}, y 1}}{L_{y, 0}}$,
$\frac{\mathrm{d} h_{\mathrm{s}, y 2}}{\mathrm{~d} t}=-\frac{\mathrm{d} h_{\mathrm{s}, y 1}}{\mathrm{~d} t}=\frac{2}{A_{0}(t)} \int_{0}^{1} v L_{x} h \mathrm{~d} \xi$,
$\frac{\mathrm{d} h_{\mathrm{s}, x 2}}{\mathrm{~d} t}=-\frac{\mathrm{d} h_{\mathrm{s}, x 1}}{\mathrm{~d} t}=\frac{2}{A_{0}(t)} \int_{0}^{1} u L_{y} h \mathrm{~d} \xi$,

where $L_{x}$ and $L_{y}$ are the sizes of the horizontal water body intersection in $x$ and $y$ directions respectively, and subscript "0" denotes values at the lake surface. For simplicity, in the model we approximate the lake's horizontal cross section, $A(z)$ as an ellipse, so that $L_{x}$ stands for the major semi-axis and $L_{y}$ the same for the minor semi-axis, or vice versa. Equations (9)-(10) express the change of surface level of four lake's sections ( $h_{\mathrm{s}, x 1}$ being the mean of $h_{\mathrm{s}}$ over the "left" section of a lake, $x<x_{\mathrm{c}}, h_{\mathrm{s}, x 2}$ the same for the "right" lake section $x>x_{\mathrm{c}}, h_{\mathrm{s}, y 1}$ the mean for $y<y_{\mathrm{c}}, h_{\mathrm{s}, y 2}$ the mean for $y>y_{\mathrm{c}}$ and $\left(x_{\mathrm{c}}, y_{\mathrm{c}}\right)$ standing for the lake centre) due to volume discharge through two vertical planes, $x=x_{\mathrm{c}}$ and $y=y_{\mathrm{c}}$ (Fig. 1), neglecting inflows and outflows. The multiplier $\pi^{2} / 4$ in Eqs. (7)-(8) arises instead of the "natural" choice of 2 in order for the solution of the model equations for the specific case of a rectangular channel to match the period of the first surface seiche mode, i.e. the Merian formula (Merian, 1828) (see Appendix C for mathematical development). According to this, the output of the LAKE model for the case of a 1-D flow developing along a non-rotating channel after initial disturbance of the lake surface demonstrates oscillations with a period very close to that predicted by Merian formula (not shown here). In the following, we will refer to Eqs. (7)-(10) as either "surface seiche parameterization" or "dynamic pressure gradient parameterization".

Boundary conditions for momentum equations are momentum flux from the atmosphere, calculated according to air surface layer bulk formulae (Paulson, 1970; Businger et al., 1971; Beljaars and Holtslag, 1991), and friction at the deepest part of bottom following quadratic dependence on velocity using the Chézy coefficient. Momentum flux accelerating currents is parameterized as a fraction of total momentum flux from the atmosphere (Stepanenko et al., 2014), because in conditions of limited fetch (small lakes) a part of total momentum flux is consumed by wave development. Partitioning momentum flux between waves and in-water currents significantly reduces shear-driven vertical mixing during summertime. 


\subsection{Turbulence closure}

The turbulence closure is a $k-\epsilon$ model with Canuto stability functions (Canuto et al., 2001). Non-turbulent flux, $\overline{F_{\mathrm{n} z}}$ in Eq. (4), is put to zero, because this model does not include any fluxes of $k$ and $\epsilon$ besides advection and turbulent transport. We also neglect advection of TKE and dissipation rate by inlets and outlets (term I in Eq. 4), because there are no observation data or reasonable ways to theoretically estimate $k$ and $\epsilon$ in streams. Marginal flux is set as $F_{\mathrm{tz}, \mathrm{b}}=0$ for TKE, which is an exact boundary condition for logarithmic layer. For $\epsilon, F_{\mathrm{t} z, \mathrm{~b}}$ is set to 0 as well, because the non-zero flux condition for TKE dissipation in the logarithmic layer (Burchard and Petersen, 1999) cannot be realized in this model framework (variables entering this condition are not available in the bottom boundary layer as they are averaged over the horizontal). The top and bottom boundary conditions for TKE and dissipation equations are the logarithmic layer (Burchard and Petersen, 1999). Sinks and sources of TKE and dissipation rate, i.e. the buoyancy term and shear production, hidden in $\overline{R_{f}}$ of Eq. (4), are approximated using only vertical derivatives of horizontally averaged temperature, salinity and velocity components. For constants of the $k-\epsilon$ model used in this study, see Appendix B.

In our study the turbulence closure briefly described above will be referred to as "standard $k-\epsilon$ model". Pertinent to objectives of the study, we will also use extensions of the standard $k-\epsilon$ model to account for specific mixing mechanisms in the thermocline, namely gravity waves (Mellor, 1989) and internal seiches (Goudsmit, 2002).

\subsection{Heat and moisture processes in sediments}

Snow and ice modules are not used in this study. Processes in sediments are treated inside a set of 3-D figures, which all have the same vertical dimension, $h_{\text {sed }}$, and the horizontal intersections of which are confined by sequential isobaths (Fig. 2). In all such columns, all properties of sediments are assumed to be horizontally homogeneous, so that only the vertical transport of heat and other quantities applies. Each column of sediments exchanges heat and $\mathrm{CH}_{4}$ with the horizontal water layer bounded from below and above by respective isobath levels according to continuity of flux and a quantity considered (temperature, $\mathrm{CH}_{4}$ concentration, see Sect. 2.2).

The heat processes in the model include vertical transport and phase transition between water and ice. The vertical transport in sediments is described according to Côté and Konrad (2005). Liquid water is transported via gravity and capillary-sorption forces (Stepanenko and Lykossov, 2005). The latter are represented by a diffusion-like term. The bottom boundary condition for temperature is the geothermal heat flux, usually set to zero. For moisture, saturation of sediments is used for the top boundary and zero flux is applied at the bottom.

\subsection{Biogeochemistry and transport of $\mathrm{CH}_{4}, \mathrm{CO}_{2}$ and $\mathrm{O}_{2}$}

The general scheme representing sources, sinks and transport mechanisms governing concentration of $\mathrm{CH}_{4}, \mathrm{CO}_{2}$ and $\mathrm{O}_{2}$ in the model is given in Fig. 3.

\subsubsection{Methane in sediments}

An elaborate description of the $\mathrm{CH}_{4}$ model in sediments can be found in Stepanenko et al. (2011), whereas here we provide a general overview and later amendments to the model presented therein. This model is applied in every column of sediments under a lake.

In each column of sediments (Sect. 2.5) $\mathrm{CH}_{4}$ transport is considered to be vertical only. The governing equation for the bulk $\mathrm{CH}_{4}$ concentration, $\mathrm{C}_{\mathrm{CH}_{4}}$, reads

$$
\begin{aligned}
\frac{\partial C_{\mathrm{CH}_{4}, \mathrm{~s}}}{\partial t} & =\frac{\partial}{\partial z} k_{\mathrm{CH}_{4}, \mathrm{~s}} \frac{\partial C_{\mathrm{CH}_{4}, \mathrm{~s}}}{\partial z_{\mathrm{s}}}+P_{\mathrm{CH}_{4}, \mathrm{~s}}-E_{\mathrm{CH}_{4}, \mathrm{~s}} \\
& -O_{\mathrm{CH}_{4}, \mathrm{~s}},
\end{aligned}
$$

where $k_{\mathrm{CH}_{4}, \mathrm{~s}}$ designates molecular diffusivity of $\mathrm{CH}_{4}, P_{\mathrm{CH}_{4}, \mathrm{~s}}$ the production rate, $E_{\mathrm{CH}_{4}, \mathrm{~s}}$ the ebullition rate, $O_{\mathrm{CH}_{4}, \mathrm{~s}}$ the aerobic oxidation rate (anaerobic oxidation is omitted) and $z_{\mathrm{s}}$ denotes a vertical coordinate originating at the column top. Vegetation uptake of $\mathrm{CH}_{4}$ by roots and aerenchyma transport are neglected in this study. The $\mathrm{CH}_{4}$ production rate is confined to the upper part of a sediment column and controlled by temperature by exponential dependence:

$$
\begin{gathered}
P_{\mathrm{CH}_{4}, \mathrm{~s}}=P_{0} \exp \left(-\alpha_{\text {new }} z_{\mathrm{s}}\right) H\left(T-T_{\mathrm{mp}}\right) q_{10}^{T / 10} \\
\left(1+\alpha_{\mathrm{O}_{2}, \text { inhib }} C_{\mathrm{O}_{2}, \mathrm{~s}}\right)^{-1},
\end{gathered}
$$

where $P_{0}$ is a calibrated constant reflecting the amount and quality of organic material in sediments with respect to $\mathrm{CH}_{4}$ production, $\alpha_{\text {new }}=3 \mathrm{~m}^{-1}$ a constant controlling the decrease of $\mathrm{CH}_{4}$ production with depth, $\mathrm{H}$ a step (Heaviside) function, $q_{10}=2.3$ (Liikanen et al., 2002) the temperature dependency constant, $T_{\mathrm{mp}}$ the melting point temperature, $\alpha_{\mathrm{O}_{2} \text {, inhib }}$ a constant describing the rate of inhibition of $\mathrm{CH}_{4}$ production with rise of bulk $\mathrm{O}_{2}$ concentration in sediments, $C_{\mathrm{O}_{2}, \mathrm{~s}}$. The latter constant is set as $\alpha_{\mathrm{O}_{2}, \text { inhib }}=316.8 \mathrm{~m}^{3} \mathrm{~mol}^{-1}$ to ensure 100 times inhibition of $\mathrm{CH}_{4}$ production at an $\mathrm{O}_{2}$ content of $10 \mathrm{ppm}$, implying almost complete suppression of methanogenic Archaea activity under this concentration (Borrel et al., 2011). The parameterization Eq. (12) traces back to Walter et al. (1996), the last multiplier added in this study. Deep $\mathrm{CH}_{4}$ production from old organics near the bottom of talik is included in the model (Stepanenko et al., 2011), but in the Kuivajärvi Lake simulation presented here it is switched off because this is not a thermokarst lake.

The ebullition rate, $E_{\mathrm{CH}_{4}, \mathrm{~s}}$ becomes non-zero when bulk $\mathrm{CH}_{4}$ concentration exceeds a critical value, defined by the 

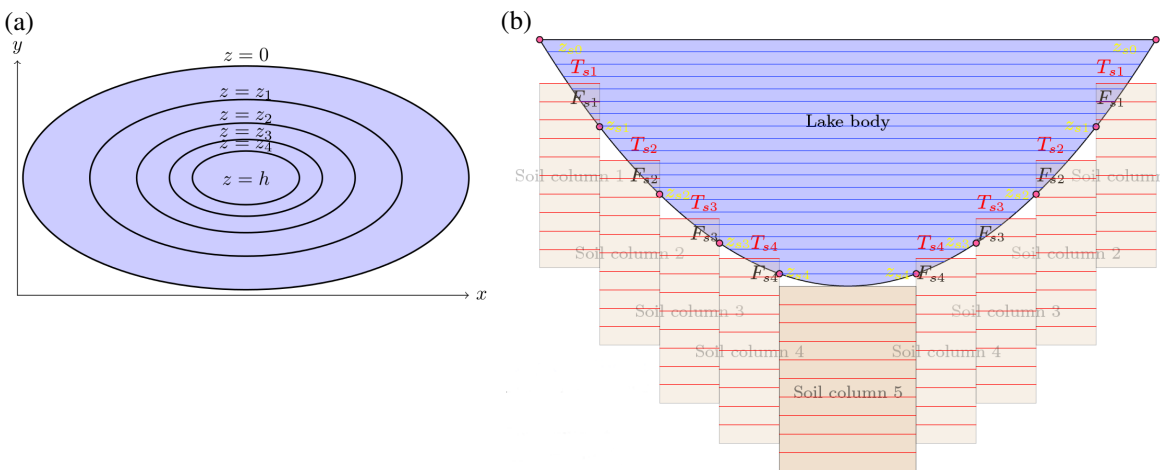

Figure 2. Horizontal and vertical cross sections of sediment columns in the LAKE model. (a) The scheme for spatial sediment column distribution. Here, horizontal cross sections of sediment columns are confined by respective isobaths; i.e. the $i$ th sediment column is bounded by $z_{i-1}$ and $z_{i}$ isobaths, $i=1, \ldots, 4$. The bottom sediment column is of an elliptic cross section. (b) Vertical cross section of a water body and sediment columns in the LAKE model, horizontal lines standing for computational levels.

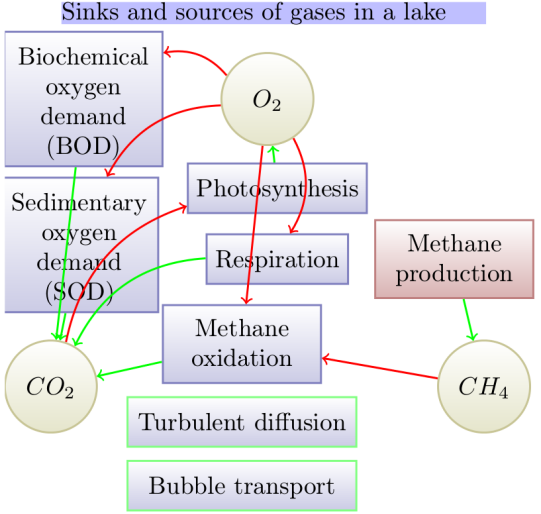

Figure 3. The $\mathrm{CH}_{4}, \mathrm{CO}_{2}, \mathrm{O}_{2}$ storages and their interaction through biogeochemical processes in the model. Green arrows are sources, red arrows are sinks. Methane production is considered in sediments while other processes take place in water bodies.

hydrostatic load of the water column and sediments layer above at a given depth, $z_{\mathrm{s}}$, as well as by nitrogen concentration at the sediments top (Stepanenko et al., 2011; Walter et al., 1996). Retention of bubbles in a sediment's skeleton (Scandella et al., 2011) is neglected so that the $\mathrm{CH}_{4}$ ebullition flux at the sediment's top of the $k$ th column, $F_{B, 1, k}$, is calculated as

$F_{B, 1, k}=\int_{0}^{h_{\text {sed }}} E_{\mathrm{CH}_{4}, \mathrm{~s}} \mathrm{~d} z_{\mathrm{s}}$,

where $h_{\text {sed }}$ signifies the depth of the sediment's column.

Oxidation of $\mathrm{CH}_{4}$ in sediments takes place in the uppermost numerical layer only, where $\mathrm{O}_{2}$ concentration is assumed to deplete exponentially towards a very small value at the base of this layer. At the top, a continuity of $\mathrm{O}_{2}$ concentration across the water-sediments interface is applied.
Then, a mean bulk $\mathrm{O}_{2}$ concentration over the top numerical layer is calculated from an exponential law. Given the bulk $\mathrm{O}_{2}$ concentration, $\mathrm{C}_{\mathrm{O}_{2}, \mathrm{~s}}$, aerobic $\mathrm{CH}_{4}$ oxidation is calculated according to Michaelis-Menten kinetics

$O_{\mathrm{CH}_{4}, \mathrm{~s}}=V_{\mathrm{max}, \mathrm{s}} \frac{C_{\mathrm{CH}_{4}, \mathrm{~s}}}{K_{\mathrm{CH}_{4}, \mathrm{~s}}+C_{\mathrm{CH}_{4}, \mathrm{~s}}} \frac{C_{\mathrm{O}_{2}, \mathrm{~s}}}{K_{\mathrm{O}_{2}, \mathrm{~s}}+C_{\mathrm{O}_{2}, \mathrm{~s}}}$,

where $V_{\mathrm{max}, \mathrm{s}}=1.11 \times 10^{-5} \mathrm{~mol}\left(\mathrm{~m}^{3} \mathrm{~s}\right)^{-1}, K_{\mathrm{CH}_{4}, \mathrm{~s}}=9.5 \times$ $10^{-3} \mathrm{~mol} \mathrm{~m}^{-3}$ and $K_{\mathrm{O}_{2}, \mathrm{~s}}=2.1 \times 10^{-2} \mathrm{~mol} \mathrm{~m}^{-3}$ are $\mathrm{CH}_{4}$ oxidation potential and two half-saturation constants respectively (Lidstrom and Somers, 1984).

In order for the above scheme of $\mathrm{CH}_{4}$ oxidation and $\mathrm{CH}_{4}$ production inhibition to be realistic, the top numerical layer in sediments is set to a thickness typical for oxygenated layers in lake's sediments, $1 \mathrm{~cm}$ (Huttunen et al., 2006).

\subsubsection{Methane in water}

The methane concentration in water evolves according to Eq. (4) with term I representing the input of $\mathrm{CH}_{4}$ by inlets and its outflow by outlets (not taken into account in this study). The diffusion coefficient, $k_{\mathrm{CH}_{4}, \mathrm{w}}$, is set equal to heat conductivity (turbulent Lewis number $L e=1$ ); the nonturbulent vertical flux is a $\mathrm{CH}_{4}$ bubble flux (see Sect. 2.7). The marginal diffusive flux is calculated from the condition of continuity of both the concentration and flux at the watersediment interface (see more in Sect. 2.2), and $R_{f}$ represents only $\mathrm{CH}_{4}$ oxidation. Aerobic $\mathrm{CH}_{4}$ oxidation in water follows Michaelis-Menten kinetics (Eq. 14) with the respective constants $V_{\text {max,w }}=1.16 \times 10^{-5} \mathrm{~mol}\left(\mathrm{~m}^{3} \mathrm{~s}\right)^{-1}$ (Liikanen et al., 2002), $K_{\mathrm{CH}_{4} \text {,w }}=3.75 \times 10^{-2} \mathrm{~mol} \mathrm{~m}^{-3}$ (Liikanen et al., 2002; Lofton et al., 2013) and $K_{\mathrm{O}_{2}, \mathrm{w}}=2.1 \times 10^{-2} \mathrm{~mol} \mathrm{~m}^{-3}$ (Lidstrom and Somers, 1984). 


\subsubsection{Oxygen and carbon dioxide in water}

Oxygen concentration is simulated by Eq. (4) with term I neglected, assuming the turbulent Lewis number to be 1 with marginal diffusive flux treated as sedimentary oxygen demand (SOD). Other sinks of $\mathrm{O}_{2}$ are biochemical oxygen demand (BOD; excluding respiration), respiration and $\mathrm{CH}_{4} \mathrm{Ox}-$ idation. Methane oxidation bacteria consume $\mathrm{O}_{2}$ according to a widely accepted stoichiometric relation

$\mathrm{CH}_{4}+2 \mathrm{O}_{2}=\mathrm{CO}_{2}+2 \mathrm{H}_{2} \mathrm{O}$,

providing the rates of $\mathrm{O}_{2}$ consumption and $\mathrm{CO}_{2}$ production given the rate of $\mathrm{CH}_{4}$ loss (Sect. 2.6.2). The only process producing $\mathrm{O}_{2}$ in a water column is photosynthesis. For biochemical oxygen demand, respiration and photosynthesis we use parameterizations from Stefan and Fang (1994). These parameterizations assume the rates of biogeochemical processes to depend exponentially on temperature and be proportional to chlorophyll $a$ concentrations. Photosynthesis is additionally limited by photosynthetic active radiation. In our simulations, we kept the original empirical constant values from Stefan and Fang (1994). For more details an interested reader may refer to the original paper.

As for sedimentary oxygen demand, we adopted the formulation from Walker and Snodgrass (1986), as it involves explicitly the near-bottom $\mathrm{O}_{2}$ concentration (via diffusive term), in contrast to that from Stefan and Fang (1994), where $\mathrm{SOD}$ continues to be non-zero even when $\mathrm{O}_{2}$ content in water is zero.

Carbon dioxide in water is calculated by the same type of prognostic equation as that for other gases. The only sink of $\mathrm{CO}_{2}$ in the water column is photosynthesis, whereas its production in the model is provided by SOD, BOD, respiration and $\mathrm{CH}_{4}$ oxidation. As the rates of these processes in terms of $\mathrm{O}_{2}$ and $\mathrm{CH}_{4}$ are quantified above, the respective income or loss of $\mathrm{CO}_{2}$ is immediately provided by Eq. (15) and the following stoichiometric equality:

$6 \mathrm{CO}_{2}+12 \mathrm{H}_{2} \mathrm{O}+$ photons $=$

$\mathrm{C}_{6} \mathrm{H}_{12} \mathrm{O}_{6}+6 \mathrm{O}_{2}+6 \mathrm{H}_{2} \mathrm{O}$,-photosynthesis and respiration,

$\mathrm{C}+\mathrm{O}_{2}=\mathrm{CO}_{2},-\mathrm{BOD}$ and SOD.

\subsubsection{Diffusive gas flux at the water-air interface}

The top boundary condition (at the lake-atmosphere interface) for the concentration of any dissolved gas has the form

$\left.k_{s} \frac{\partial C_{\mathrm{w}}}{\partial z}\right|_{z=0}=F_{C_{\mathrm{w}}}$

where $C_{\mathrm{w}}$ is $C_{\mathrm{CH}_{4}, \mathrm{w}}, C_{\mathrm{O}_{2}, \mathrm{w}}$ or $C_{\mathrm{CO}_{2}, \mathrm{w}}, k_{s}$ the dissolved gas diffusion coefficient and $F_{C_{\mathrm{w}}}$ is the diffusive flux of a gas into the atmosphere, which is positive upwards. This flux is calculated according to the widely used parameterization

$F_{C_{\mathrm{w}}}=k_{\mathrm{ge}}\left(\left.C_{\mathrm{w}}\right|_{z=0}-C_{\mathrm{ae}}\right)$,

with $C_{\text {ae }}$ being the concentration of the gas in water equilibrated with the atmospheric concentration following Henry's law and $k_{\mathrm{ge}}, \mathrm{m} \mathrm{s}^{-1}$, denoting the gas exchange coefficient, the so-called "piston velocity". The latter is written as

$k_{\mathrm{ge}}=k_{600} \sqrt{\frac{600}{S c(T)}}$,

with the Schmidt number $S c(T)$ having individual values for different gases and being temperature dependent. The $k_{600}$ coefficient has been a subject of numerous studies, and a number concepts have been proposed to quantify it (Donelan et al., 2002). We adopt two widespread options for $k_{600}$ : (i) empirical dependence on wind speed and (ii) the surface renewal model.

The dependency on wind velocity takes the form (Cole and Caraco, 1998)

$k_{600}=C_{k_{600}, 1}+C_{k_{600}, 2}\left|\boldsymbol{u}_{\mathrm{a}, 10}\right|^{n_{k_{600}}}$.

Here, $\boldsymbol{u}_{\mathrm{a}, 10}$ stands for the wind speed vector at $10 \mathrm{~m}$ above the water surface, and $C_{k_{600}, 1}=5.75 \times 10^{-6} \mathrm{~m} \mathrm{~s}^{-1}$ and $C_{k_{600}, 2}=$ $5.97 \times 10^{-6}\left(\mathrm{~m} \mathrm{~s}^{-1}\right)^{1-n_{k 000}}$ are empirical constants. The simple empirical Eq. (21) "integrates" the effects of wind speed on a number of processes such as turbulence in adjacent layers of water and air, wave development and breaking, cool skin dynamics, and therefore is likely not to be sophisticated enough to express adequately a wide variety of conditions met on real lakes. Therefore, we also included the surface renewal model (MacIntyre et al., 2010; Heiskanen et al., 2014), which in terms of $k_{600}$ states that

$k_{600}=\frac{C_{1, \mathrm{SR}}\left(\left.\epsilon\right|_{z=0} \nu_{\mathrm{m}}\right)^{\frac{1}{4}}}{\sqrt{600}}$,

where $v_{\mathrm{m}}$ designates molecular viscosity of water and $C_{1, \mathrm{SR}}=0.5$ is an empirical parameter. As TKE dissipation rate is available directly from $k-\epsilon$ closure, we do not use any special parameterization for $\left.\epsilon\right|_{z=0}$ as proposed in other work (e.g. MacIntyre et al., 2010).

\subsection{Bubble model and its coupling to the LAKE model}

\subsubsection{Single bubble model}

The bubble model used in LAKE closely follows that described in McGinnis et al. (2006). Consider the evolution of 
a bubble rising from the lake bottom, and consisting of a mixture of gases. The quantity of each $i$ th gas in the bubble, $M_{i}$, mol, changes due to its dissolution into the water according to the following equation:

$$
\begin{aligned}
& \frac{\mathrm{d} M_{i}}{\mathrm{~d} t}=v_{\mathrm{b}} \frac{\mathrm{d} M_{i}}{\mathrm{~d} Z}=-4 \pi r_{\mathrm{b}}^{2} K_{i}\left(H_{i}(T) P_{i}-C_{i}\right), \\
& \quad i=1, \ldots, n_{\mathrm{g}},
\end{aligned}
$$

where $r_{\mathrm{b}}$ is the bubble radius, $H_{i}$ the Henry's "constant" dependent on temperature $T, P_{i}$ the partial pressure of $i$ th gas, $C_{i}$ the molar concentration of a gas in water, $K_{i}$ the exchange coefficient, $v_{\mathrm{b}}$ the bubble vertical velocity and $Z$ the vertical coordinate originating at the bottom and pointing opposite to gravity, $n_{\mathrm{g}}$ is the number of gases in a mixture.

Five gases are considered in a bubble: $\mathrm{CH}_{4}, \mathrm{CO}_{2}, \mathrm{O}_{2}$, $\mathrm{N}_{2}$ and Ar. Water vapour constitutes a minor contribution to bubble pressure, and is therefore neglected. Indeed, the saturated vapour pressure at $20^{\circ} \mathrm{C}$ is $23.4 \mathrm{hPA}$, i.e. $\approx 2 \%$ of atmospheric pressure. This is the upper estimate for the water vapour pressure contribution in bubbles, as the pressure increases with depth, and saturation vapour pressure decreases, due to water temperature drop. Similar estimates hold for Ar, though it is formally included in the bubble model.

The temperature in the bubble is assumed to be equal to that of environmental limnetic water at the depth of the current bubble location, $Z$. It means that the heat exchange between the rising bubble and water is expected to be intensive enough to dominate over the adiabatic cooling of the bubble. In practical terms, this frees us from solving an additional equation for bubble temperature. The temperature dependency of Henry's constants for a flat solution surface is taken from Sander (1999). The effect of gas-water interface curvature on equilibrium gas pressure is omitted in this model because when using the Thomson (Kelvin) formula it turns out to be negligible for typical bubble radii in oceans and lakes $(\geq 1 \mathrm{~mm})$. The exchange coefficient, $K_{i}$, is dependent on molecular diffusivity in water, bubble radius and its velocity according to empirical formulae from Zheng and Yapa (2002). The bubble velocity is determined assuming equilibrium between buoyancy force and environment resistance given by the quadratic law for small radii $\left(r_{\mathrm{b}}<1.3 \mathrm{~mm}\right)$ and taking into account the bubble surface oscillations for larger sizes (Jamialahmadi et al., 1994).

For each component of the gas mixture, we apply an ideal gas law because under the typical pressures at moderate water depths (at least dozens of metres) Van der Waals forces are small:

$$
\frac{4}{3} P_{i} \pi r_{\mathrm{b}}^{3}=M_{i} R T, i=1, \ldots, n_{\mathrm{g}},
$$

where $R$ is the universal gas constant. The surface tension pressure is small for the bubbles with radii typical in a la- custrine environment, and is neglected in Eq. (24). Then, when equating the gas mixture pressure $\sum_{i=1}^{n_{\mathrm{g}}} P_{i}$ to hydrostatic pressure at a given depth, $p_{\mathrm{a}}+\rho_{\mathrm{w} 0} g\left(h_{\mathrm{bot}}-Z\right)\left(p_{\mathrm{a}}\right.$ is the atmospheric pressure; $h_{\text {bot }}$ is a lake depth in a point, where the bubble is released) and using Eq. (24) one yields

$r_{\mathrm{b}}=\left[\frac{3 R T \sum_{i=1}^{n_{\mathrm{g}}} M_{i}}{4 \pi\left(p_{\mathrm{a}}+\rho_{\mathrm{w} 0} g\left(h_{\mathrm{bot}}-Z\right)\right)}\right]^{1 / 3}$.

For the solution of $2 n_{\mathrm{g}}+1$ (Eqs. 23-25) the boundary conditions are needed. These are initial gases' molar quantities $M_{i, Z=0}=M_{i 0}(t), i=1, \ldots, n_{\mathrm{g}}$, which are the quantities at the moment when the bubble crosses the lake bottom. In the model they are initialized as follows:

$M_{i 0}=\alpha_{i} M_{0}, i=1, \ldots, n_{\mathrm{g}}$,

$M_{0}=\frac{\frac{4}{3} \pi r_{\mathrm{b} 0}^{3}\left(p_{\mathrm{a}}+\rho_{\mathrm{w} 0} g h_{\mathrm{bot}}\right)}{\left.R T\right|_{Z=0}}$,

where $M_{0}$ the total gas quantity in the bubble (mols). According to Eq. (26), the bubble initialization is provided by the initial bubble radius, $r_{\mathrm{b} 0}$, and molar fractions of mixture components $\alpha_{i}$. In this study, we chose $r_{\mathrm{b} 0}=2 \times 10^{-3} \mathrm{~m}$ and the initial bubble gas composition to be $100 \%$ of $\mathrm{CH}_{4}$.

The bubble model described above is numerically solved by the Euler explicit scheme.

\subsubsection{Bubble flux of gases}

In Eq. (4), applied for $\mathrm{CH}_{4}, \mathrm{O}_{2}$ and $\mathrm{CO}_{2}$, the non-turbulent flux (term III) consists of bubble flux only. Bubble flux also contributes to term IV therein. This section explains how these terms are evaluated using the single bubble model, described above (Sect. 2.7.1).

We consider an idealized situation when all bubbles rising from all columns of sediments have the same initial radius $r_{\mathrm{b} 0}$ at the bottom and identical gas composition. Given that in reality there is always a variety in the size of the bubbles, parameter $r_{\mathrm{b} 0}$ may be treated as an average (in appropriate sense) radius over this distribution. For bubbles rising from a given sediment column, Eqs. (23)-(25) imply that their radius and composition will be the same at any level over this column.

Now, at any depth $z$ we can construct a horizontal average of vertical bubble flux of the $i$ th gas, $\overline{F_{B, i}}(z) \approx$ $A^{-1}(z) \sum_{k=1}^{n_{s}} F_{B, i, k}(z) A_{k}(z)$, where index $k$ is the index of a sediment column, $n_{s}$ a total number of columns and $A_{k}(z)$ an area of projection onto $A(z)$ of the part of the top facet of the $k$ th column residing below depth $z$ (e.g. for columns with tops above $z, A_{k}(z)=0$; for columns of sediment with top facets completely below $z, A_{k}(z)=A_{s, k}$, where $A_{s, k}$ stands for the area of top facet of the $k$ th column). When the mean 
flux is calculated, it may be used in term III of Eq. (4)

$+\frac{1}{A} \frac{\partial A \overline{F_{B, i}}}{\partial z}$

Here $F_{B, i}$ is defined as positive upwards leading to a "+" sign.

To get the averaged flux $\overline{F_{B, i}}$ as described above, the individual bubble fluxes $F_{B, i, k}$ are calculated from each sediment column as

$F_{B, i, k}=M_{i, k} n_{\mathrm{b}, k} v_{b, k}$

Here, we introduced the bubble number density $n_{\mathrm{b}, k}, \mathrm{~m}^{-3}$, and $k$ is a sediment column index, as before. All bubbles that are released from a given sediment column's surface completely dissolve simultaneously at some depth or evade to the atmosphere. Furthermore, it is known that bubbles with a diameter $\approx 1 \mathrm{~cm}$ are unstable and split up (Yamamoto et al., 2009; McGinnis et al., 2006). Hence, in the model it is assumed that a bubble with $r_{\mathrm{b}} \geq 0.5 \mathrm{~cm}$ splits into two. In the depth interval between two subsequent bubble collapses, the bubble flux (i.e. the number of bubbles crossing the horizontal surface of $1 \mathrm{~m}^{2}$ per $1 \mathrm{~s}$ ) is constant, and at the depth of the division it doubles. Taking this into account, one may rewrite Eq. (28) as follows:

$F_{B, i, k}=F_{B, i, k}\left(h_{\text {bot }}\right) N_{k} m_{i, k}$,

where we have used the product $N_{k} m_{i, k}$ AS the bubble flux normalized by the bottom value, with $m_{i, k}=$ $M_{i, k} / M_{i, k}\left(h_{\text {bot }}\right), N_{k}=\left(n_{\mathrm{b}, k} v_{b, k}\right) /\left(n_{\mathrm{b}, k}\left(h_{\mathrm{bot}}\right) v_{b, k}\left(h_{\mathrm{bot}}\right)\right)$ and $F_{B, i, k}\left(h_{\text {bot }}\right)$ stands for the bubble flux at the bottom (top of $k$ th column of sediments). Evidently, $N_{k}(z)=2^{l}, l$ is the number of bubble divisions that happened below depth $z$ over the $k$ th sediment column. If the bottom bubble flux of one gas is known (in this model it is $\mathrm{CH}_{4}, i=1$; see Sect. 2.6.1) then the bottom fluxes of other gases are determined by bottom bubble composition:

$$
F_{B, i, k}\left(h_{\mathrm{bot}}\right)=F_{B, 1, k}\left(h_{\mathrm{bot}}\right) \frac{\alpha_{i}}{\alpha_{1}}, i=2, \ldots, n_{\mathrm{g}} \text {. }
$$

\subsection{Numerical aspects}

The principal requirements for the numerical scheme of the diffusion-type model with non-linear sources described above are an integral conservation of prognostic variables and stability.

Integral conservation is achieved by employing secondorder centred differences in space for all equations in water and sediments. The coupling of sediment columns to a water body is also implemented ensuring continuity of heat and $\mathrm{CH}_{4}$ flux across the sediments-water interface.
Equations of the $k-\epsilon$ closure are discretized in a way where TKE input by shear production and buoyancy in the TKE equation equals dissipation and potential energy source/sink in momentum and temperature/salinity equations respectively (Burchard, 2002) (salinity is set to zero in this study).

The time-marching scheme is a Crank-Nicolson scheme (Crank and Nicolson, 1996) that allows for increased time steps, $\Delta t \approx 10 \mathrm{~min}$ for vertical grid spacing of $\approx 1 \mathrm{~m}$ in water, if not using surface seiche parameterization. The time step is limited due to high non-linearity of the $k-\epsilon$ closure. However, the strongest constraint for the time step arises when horizontal pressure gradients are calculated via mass conservation (Eqs. 7)-(10). These equations are solved by an explicit scheme, and $\Delta t$ in this case should be less then the period of basin-scale surface seiche oscillations, estimated to be $\sim 1$ min from the Merian formula for Kuivajärvi Lake.

Using the Crank-Nicolson scheme in momentum equations allows for eliminating the Coriolis terms in a kinetic energy equation.

The algorithmic implementation of the model numerical scheme is presented as a flowchart in Fig. 4.

\section{The lake measurements and model set-up}

\subsection{Measurements}

Lake Kuivajärvi is a small (area $0.63 \mathrm{~km}^{2}$ ) boreal lake in Hyytiälä, southern Finland ( $24^{\circ} 16^{\prime} \mathrm{E}, 61^{\circ} 50^{\prime} \mathrm{N}$; $141 \mathrm{~m}$ a.s.1.) next to the well-established SMEAR II forest station (Hari and Kulmala, 2005). The lake has an elongated shape extending about $2.6 \mathrm{~km}$ in north-west to south-east direction and having a maximal width of $400 \mathrm{~m}$. The catchment area is $9.4 \mathrm{~km}^{2}$ of mostly flat terrain with the primary soil type of Haplic Podzol, and the vegetation is mostly managed pine forest. The lake has a maximum and mean depth of 13.2 and $6.4 \mathrm{~m}$ respectively. Fluxes of momentum, sensible and latent heat are measured at $1.5 \mathrm{~m}$ above the lake surface with an eddy covariance (EC) technique. The measurement setup consisting of an ultrasonic anemometer (USA-1, Metek $\mathrm{GmbH}$, Germany) and an enclosed-path infrared gas analyser (LI-7200, LI-COR Inc., Nebraska, USA) is mounted on a fixed platform situated in the middle of the lake. More details on the measurement platform, the EC system set-up and flux calculation procedures can be found in Mammarella et al. (2015). On the platform, a four-way net radiometer (CNR-1) provided the full radiation budget (shortwave and longwave) and a thermistor string of $16 \mathrm{Pt} 100$ resistance thermometers (accuracy of $0.2^{\circ} \mathrm{C}$, depths $0.2,0.5,1.0,1.5,2.0$, $2.5,3.0,3.5,4.0,4.5,5.0,6.0,7.0,8.0,10.0$ and $12.0 \mathrm{~m})$ enabled the calculation of the heat storage in water and the thermocline depth according to Nordbo et al. (2011). All the atmospheric measurements were performed at the height of $1.7 \mathrm{~m}$ above the water and $30 \mathrm{~min}$ averages were calcu- 


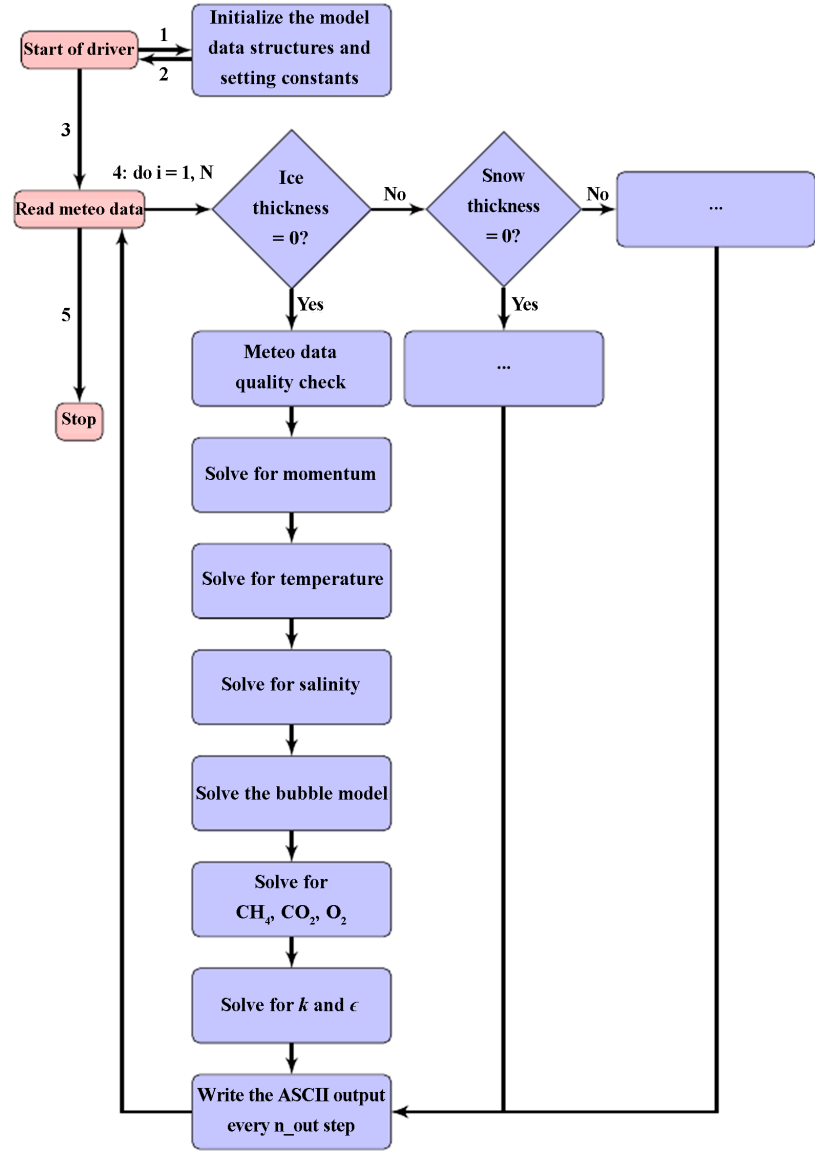

Figure 4. The flowchart of the LAKE model. Pink boxes are operations of the driving program unit (may be an atmospheric/climate model). Blue boxes are operations of the model itself, $N$ standing for the number of time steps, and $n \_$out - for the period of output (time steps). Each iteration of a cycle "do $i=1, N$ " performs one time step of the model.

lated for the analyses. In addition, the relative humidity (RH) was directly measured at the platform at the height of $1.5 \mathrm{~m}$ (MP102H-530300, Rotronic AG, Switzerland). Manual water samplings for $\mathrm{CO}_{2}$ and $\mathrm{CH}_{4}$ were conducted weekly in the water column from the surface to the bottom $(0.1,1,3,5$, $7,9,11$ and $12 \mathrm{~m})$. The $\mathrm{O}_{2}$ content was measured every halfmetre until the depths of $9 \mathrm{~m}$ and after that every $1 \mathrm{~m}$ (depths $0.1,0.5,1.0,1.5,2.0,2.5,3.0,3.5,4.0,4.5,5.0,5.5,6.0,6.5$, $7.0,7.5,8.0,8.5,9.0,10.0,11.0$ and $12.0 \mathrm{~m})$. These samples were processed using the headspace equilibrium technique as described in Miettinen et al. (2015). The used data are for the period 5 May to 31 October 2013.

\subsection{Set-up of numerical experiments}

Numerical experiments with the LAKE model were arranged in a way to fit the main objectives of the study: (i) general assessment of model performance in temperature, $\mathrm{O}_{2}, \mathrm{CO}_{2}$ and $\mathrm{CH}_{4}$, and (ii) quantification of the role of lake strati-
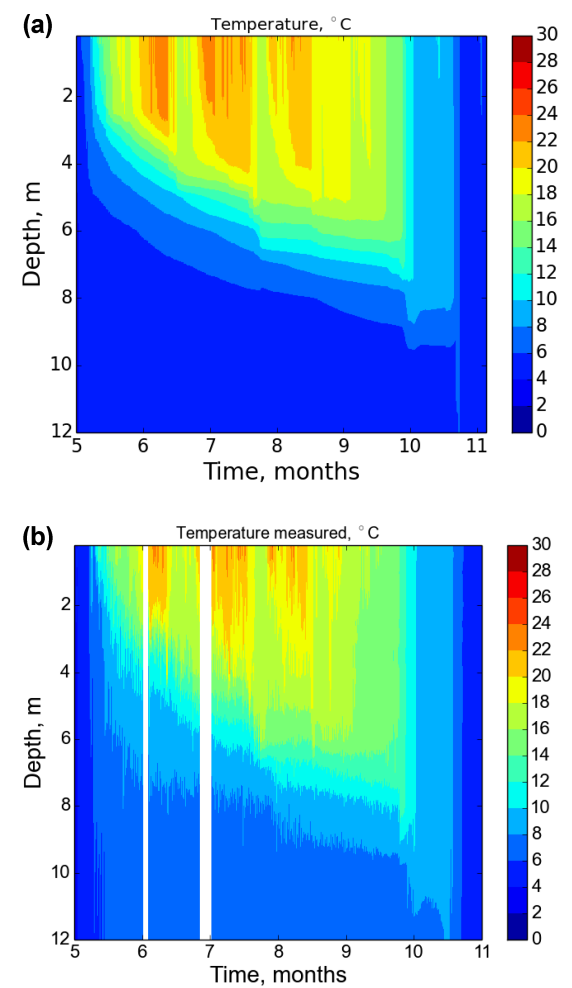

Figure 5. Time-depth distribution of temperature in Kuivajärvi Lake. Months at the horizontal axis are from 2013.

fication and turbulence regimes in the vertical transport of gases. A set of experiments consists of a baseline (reference) model run and others, where physical parameterizations or constants were varied.

The parameters of the baseline experiment are given in Table 1. Maximal lake depth was set to $12.5 \mathrm{~m}$ to ease comparison with measurements, as this is the local depth below observational mast. There is no information on the lake sediment characteristics of Kuivajärvi Lake; however, silt loam should be close in soil particle size to typical lake sediments. Sediment depth $(10 \mathrm{~m})$ is chosen to be at a depth that is enough for temperature fluctuations not to reach its lower boundary. To get $A(z)$, we linearly interpolated the morphometric data given in Table 2.

Boundary conditions were set as follows. At the sediment's bottom, zero heat and moisture fluxes were imposed. At the water surface, the heat balance equation is applied, where downward radiation fluxes were measured at the mast, surface longwave radiation calculated via the StefanBoltzmann law, and sensible and latent heat fluxes - using the Monin-Obukhov similarity functions (Table 1). In total, seven meteorological variables were supplied to the model, at 30 min intervals, all measured at the lake: wind speed and direction, temperature, humidity, longwave and shortwave radiation and atmospheric pressure. For analysis of these time series, we refer to Heiskanen et al. (2015). 
Initial conditions for the model are the profiles of all prognostic variables at an initial instant. Water temperature, $\mathrm{O}_{2}$, $\mathrm{CO}_{2}$ and $\mathrm{CH}_{4}$ vertical distributions were specified from measurements at 00:00 UTC + 03:00 5 May 2013. Salinity was set to zero and two horizontal velocity components were initialized with small values. In sediment columns, temperature was set to $4{ }^{\circ} \mathrm{C}$, and water content to slightly undersaturated values.

Only two constants in the model were calibrated. The first one is $P_{0}$ in Eq. (12), controlling the magnitude of $\mathrm{CH}_{4}$ production in sediments, representing quantity and "quality" of organics in sediments as a substrate for methanogenic activity. However, we found that this constant is not enough to regulate the $\mathrm{CH}_{4}$ concentration in the lake mixed layer (see the rationale in Sect. 5.3). A half-saturation constant in the $\mathrm{CH}_{4}$ oxidation reaction rate, $K_{\mathrm{CH}_{4} \text {, w }}$, was found to be a crucial parameter in this respect, effectively changing mean levels of mixed-layer $\mathrm{CH}_{4}$ concentration.

The sensitivity experiments were set with the same configuration as the baseline experiment, with the only modifications being

- surface seiches turned off (denoted hereafter as SS-);

- internal seiches parameterized via the Goudsmit formulation (IS+);

- gravity waves parameterized with Mellor extension for $k-\epsilon$ model $(\mathrm{GV}+)$;

- internal seiches parameterized via Goudsmit formulation, surface seiches turned off (IS+SS-);

- gravity waves parameterized with the Mellor extension for the $k-\epsilon$ model, surface seiches turned off $(\mathrm{GV}+\mathrm{SS}-)$;

- minimal diffusivity (MD) in the thermocline increased.

In the following sections we will describe and discuss the main results of the baseline experiment and sensitivity experiments in terms of physical and biogeochemical variables.

\section{Results}

\subsection{Temperature and turbulent quantities}

In this section we will consider the temperature stratification and turbulent structure of the lake vertical column, which are prerequisites for correct simulation of biogeochemical processes. The surface momentum and energy fluxes will not be covered as they were discussed for this lake involving the LAKE model results on these variables in Heiskanen et al. (2015).

Evolution of temperature distribution in the lake is presented at Fig. 5a (model) and b (observations). The temperature profile at the beginning of May is nearly homogeneous at both figures, with values close to a temperature of maximal density $\left(\approx 4^{\circ} \mathrm{C}\right)$. Then, as the net energy input in the lake becomes positive, the surface mixed layer starts to heat up, achieving temperature values of above $22^{\circ} \mathrm{C}$ in both measurements and the model by mid-June. During summer, we may distinguish three periods of warm epilimnion $\left(>22^{\circ} \mathrm{C}\right)$ interrupted by two cold periods $\left(<18^{\circ} \mathrm{C}\right)$ which are caused by change of synoptic conditions in the atmosphere. Starting from the second part of August, the net energy loss at the lake surface leads to mixed-layer cooling and eventually homogenization of the water column at about $4{ }^{\circ} \mathrm{C}$.

The model satisfactorily reproduces the observed seasonal temperature pattern in Kuivajärvi Lake. The root mean square error (RMSE) for surface temperature is $1.54^{\circ} \mathrm{C}$ and the difference of means is $0.61^{\circ} \mathrm{C}$ (the average of modelled surface temperature slightly exceeds that of observed). However, a closer look into Fig. 5b reveals high-frequency fluctuations of the observed temperature in the depth range of the thermocline, which are not reproduced by the model (Fig. 5a). These oscillations are of amplitude comparable with that of surface diurnal cycle at the surface, $1-2{ }^{\circ} \mathrm{C}$. We will address the nature and possible significance of these fluctuations in Sect. 5.1.

Figure 6 presents July-averaged profiles of TKE obtained in different model runs. In all model experiments the maximal amount of TKE is observed in the surface mixed layer, whereas the behaviour of TKE below is different depending on the experimental set-up. We see that in model runs with surface seiches switched off (marked by "SS-" in the legend) when the minimal TKE is attained below thermocline, i.e. in the hypolimnion. In contrast to these, in model launches where the barotropic pressure gradient was taken into account, TKE was produced below thermocline as well, while the TKE minimum is located inside the thermocline. Significantly, introducing Goudsmit internal-seicheinduced mixing parameterization in the model (IS+ experiment) brings a very small change to the TKE profile. On the other side, Mellor gravity wave parameterization (Mellor, 1989) (GV+ experiment) adds considerable TKE to the profile of baseline experiment, especially in metalimnion and hypolimnion in conjunction with surface seiches taken into account.

\subsection{Oxygen}

Hereafter, for gases dissolved in water, we use concentrations per unit volume of water.

Dissolved $\mathrm{O}_{2}$ evolution in Kuivajärvi Lake is presented in Fig. 7a (model, reference experiment) and Fig. 7b (observations). Here and in the subsequent plots for $\mathrm{CO}_{2}$ and $\mathrm{CH}_{4}$, we will confine our analysis to the June-October period, as during May the modelled gas concentration undergoes adjustment towards realistic patterns due to incorrect initial conditions in sediments. Large-scale features in $\mathrm{O}_{2}$ distribution agree in model and in measurements: maximal quantities of 
Table 1. Parameters of the baseline experiment.

\begin{tabular}{ll}
\hline Time span of integration & 5 May-31 October 2013 \\
Time step, $\Delta t$ & $10 \mathrm{~s}$ \\
Vertical grid & 20 layers, refined near boundaries \\
Number of columns of sediments, $n_{s}$ & 5 \\
Vertical grid in columns of sediments & 10 layers, exponentially compacting towards sediments top \\
\hline & Physical parameters \\
\hline Albedo for visible radiation & 0.06 \\
Fraction of near-infrared energy in shortwave flux & $35 \%$ \\
Water surface emissivity & 0.98 \\
Extinction coefficient for shortwave radiation & $0.58 \mathrm{~m}^{-1}$ \\
Modal wind fetch & $410 \mathrm{~m}$ \\
Maximal lake depth, $h$ & $12.5 \mathrm{~m}$ \\
Vertical dimension of sediment columns, $h_{\text {sed }}$ & $10 \mathrm{~m}$ \\
Sediment (soil) type & Silt loam \\
Lake bottom effective roughness, $z_{0 \mathrm{~b}, \text { eff }}$ & $10^{-3} \mathrm{~m}$ \\
Initial bubble radius, $r_{\mathrm{b} 0}$ & $2 \times 10^{-3} \mathrm{~m}$ \\
\hline
\end{tabular}

Physical parameterizations

Surface flux scheme

Equation of state

Paulson (1970); Businger et al. (1971); Beljaars and Holtslag (1991)

Turbulence closure

Table 2. Lake morphometry parameters.

\begin{tabular}{ll}
\hline \multicolumn{2}{c}{ Hypsometric curve } \\
\hline Depth, $z, \mathrm{~m}$ & $\begin{array}{l}\text { Horizontal cross sec- } \\
\text { tion area, } A(z), \mathrm{m}^{2}\end{array}$ \\
\hline 0 & $6.38 \times 10^{5}$ \\
1.5 & $5.41 \times 10^{5}$ \\
3 & $3.86 \times 10^{5}$ \\
6 & $2.27 \times 10^{5}$ \\
10 & $7.79 \times 10^{4}$ \\
12.5 & $7.0 \times 10^{3}$ \\
\hline
\end{tabular}

Semi-major to semi-minor axis ratio of the elliptic lake shape, $L_{x} / L_{y}$

$\mathrm{O}_{2}$ are concentrated in the mixed layer (since the photosynthesis rate is highest in the photic zone), whereas the minimal ones occur in the late summer near the bottom, due to consumption by sediments. For surface $\mathrm{O}_{2}$ concentration, the averaged absolute bias is $1.27 \mathrm{mg} \mathrm{L}^{-1}$ (model value equals to $7.84 \mathrm{mg} \mathrm{L}^{-1}$ vs. the measured value of $9.11 \mathrm{mg} \mathrm{L}^{-1}$ ), and the RMSE is $1.37 \mathrm{mg} \mathrm{L}^{-1}$.

Oxygen concentration is prominently different in the model from what was observed in the lake during spring and autumn turnovers. The model significantly underestimates $\mathrm{O}_{2}$ levels below the mixed layer in spring and throughout the water column in autumn, by $\approx 3 \mathrm{mg} \mathrm{L}^{-1}$ in the latter case. Another difference is in the vertical gradient in hypolimnion:

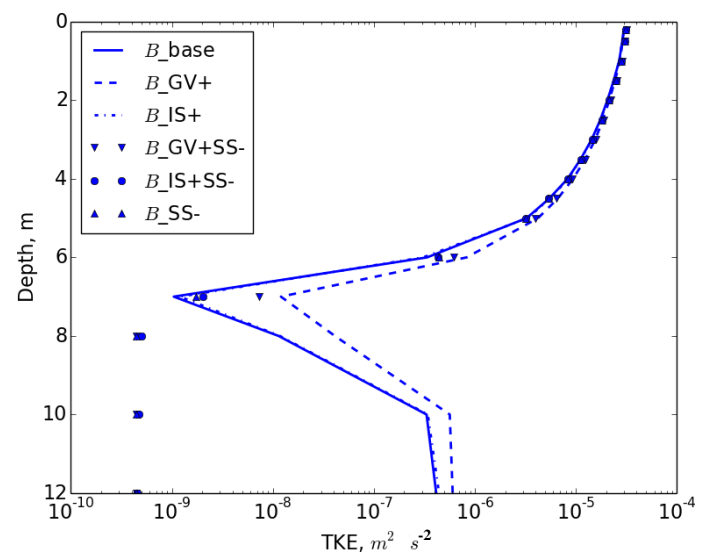

Figure 6. Mean TKE profile in Kuivajärvi Lake, July 2013, simulated. Model runs: "base" - baseline, "GV+" - including gravity waves shear parameterization (Gill, 1982; Mellor, 1989), "IS+" - including internal seiche mixing parameterization (Goudsmit, 2002), "GV+SS-" - the same as "GV+" but with surface seiches switched off, "IS+SS-" - the same as "IS+" but with surface seiches switched off, "SS-" - the same as "base" but with surface seiches switched off

the model produces a sharp gradient whereas in nature there is almost homogeneous $\mathrm{O}_{2}$ distribution.

\subsection{Carbon dioxide}

Carbon dioxide concentration distribution in water somewhat mirrors that of $\mathrm{O}_{2}$ (Fig. 8a and b). The minimum of dissolved 

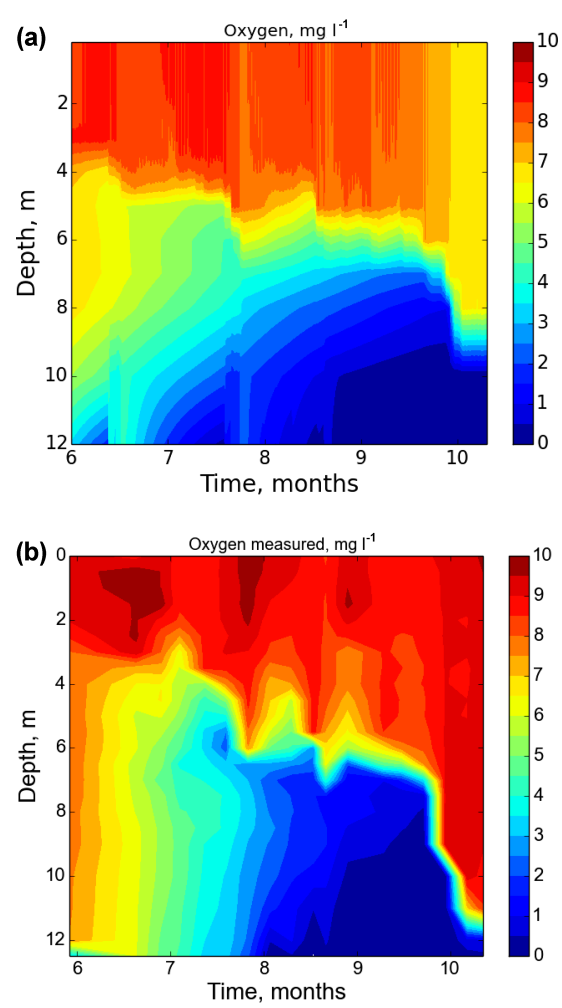

Figure 7. Time-depth distribution of dissolved $\mathrm{O}_{2}$ in Kuivajärvi Lake. Months at the horizontal axis are from 2013.

$\mathrm{CO}_{2}$ is located in the mixed layer, while below the thermocline it is continuously accumulated during summer before reaching a minimum throughout a water column at autumnal turnover. This general pattern is captured by the model.

Surface $\mathrm{CO}_{2}$ density is considerably lower in the model compared to observations (time average being $0.39 \mathrm{~m} \mathrm{~L} \mathrm{~L}^{-1}$ vs. $2.80 \mathrm{mg} \mathrm{L}^{-1}$ ) with RMSE $2.35 \mathrm{mg} \mathrm{L}^{-1}$. As in the case of $\mathrm{O}_{2}$, the modelled $\mathrm{CO}_{2}$ is characterized by high vertical gradients in hypolimnion, while the measured data demonstrate a much more homogeneous field. We also note overestimated hypolimnetic concentrations in the model until September, when an abrupt rise of $\mathrm{CO}_{2}$ was detected by manual measurements.

\subsection{Methane}

Methane concentration in the lake water is low (Fig. 9a, b), except for in late September and the beginning of October when it increases near bottom up to $351.5 \mu \mathrm{g} \mathrm{L}^{-1}$ in the model and $536.0 \mu \mathrm{g} \mathrm{L}^{-1}$ according to measurements. The model successfully reproduces this seasonal pattern, though it produces weak maxima in $\mathrm{CH}_{4}$ concentration close to sediments during summer. The observed maximum is single, while in the model, autumnal near-bottom $\mathrm{CH}_{4}$ rise is disrupted by a sharp decrease in beginning of October, leading to two concentration peaks (Fig. 9a). Similarly, one can
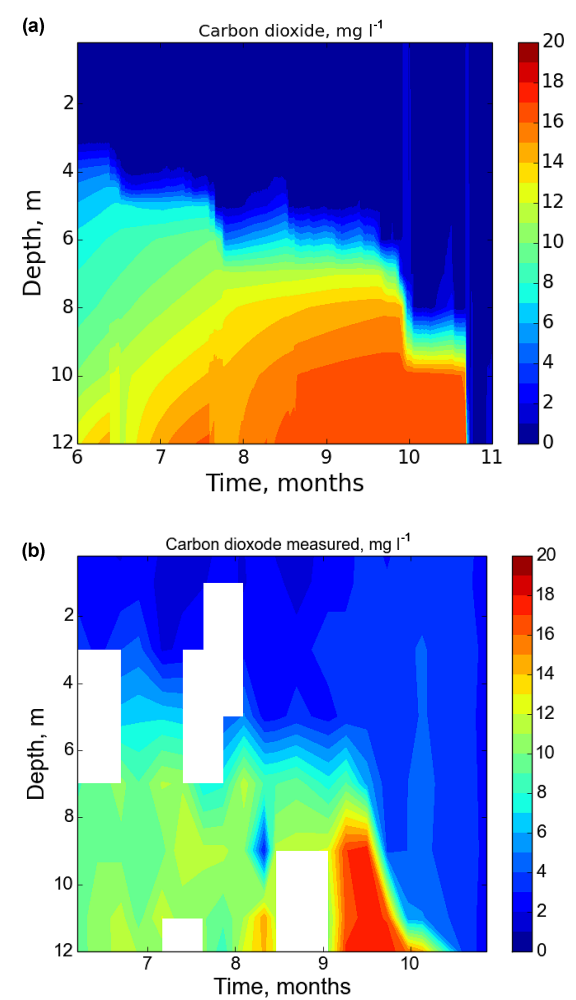

Figure 8. Time-depth distribution of dissolved $\mathrm{CO}_{2}$ in Kuivajärvi Lake. Months at the horizontal axis are from 2013.

note multiple weak near-bottom $\mathrm{CH}_{4}$ maxima during JuneAugust. The surface concentration remains small through the entire simulation time, with a mean value of $0.89 \mu \mathrm{g} \mathrm{L}^{-1}$ in the model, $1.06 \mu \mathrm{g} \mathrm{L}^{-1}$ in observations and model RMSE is $0.83 \mu \mathrm{g} \mathrm{L}{ }^{-1}$.

Due to the low $\mathrm{CH}_{4}$ level in Kuivajärvi Lake surface waters, the flux of this gas to the atmosphere is negligible; average eddy covariance $\mathrm{CH}_{4}$ flux (not shown) is only $0.0006 \mu \mathrm{mol}\left(\mathrm{m}^{2} \mathrm{~s}\right)^{-1}\left(0.8 \mathrm{mg}\left(\mathrm{m}^{2} \mathrm{day}\right)^{-1}\right)$. The average diffusive flux at the lake surface in the model is $0.0005 \mu \mathrm{mol}\left(\mathrm{m}^{2} \mathrm{~s}\right)^{-1}\left(0.7 \mathrm{mg}\left(\mathrm{m}^{2} \text { day }\right)^{-1}\right)$. Whereas diffusive flux in the LAKE model can be treated as an average one over the water body surface, bubble flux at this surface is calculated over each sediment column separately (Sect. 2.7); i.e. it is different over different lake depth zones. Therefore, to compare the total $\mathrm{CH}_{4}$ flux (diffusive plus ebullition) to eddy covariance measurements, it is the bubble flux from the sediment column located approximately below the EC footprint that should be used (for EC footprint at Kuivajärvi Lake, see Mammarella et al., 2015). In our case, it is the deepest sediment column, where the time-average $\mathrm{CH}_{4}$ ebullition flux reaching the surface constitutes $0.006 \mu \mathrm{mol}\left(\mathrm{m}^{2} \mathrm{~s}\right)^{-1}$ $\left(8 \mathrm{mg}\left(\mathrm{m}^{2} \mathrm{day}\right)^{-1}\right)$. Thus, the mean total $\mathrm{CH}_{4}$ flux in the model exceeded the observed one by an order of magnitude, still remaining low compared to that at many other lakes (Juutinen et al., 2009). 

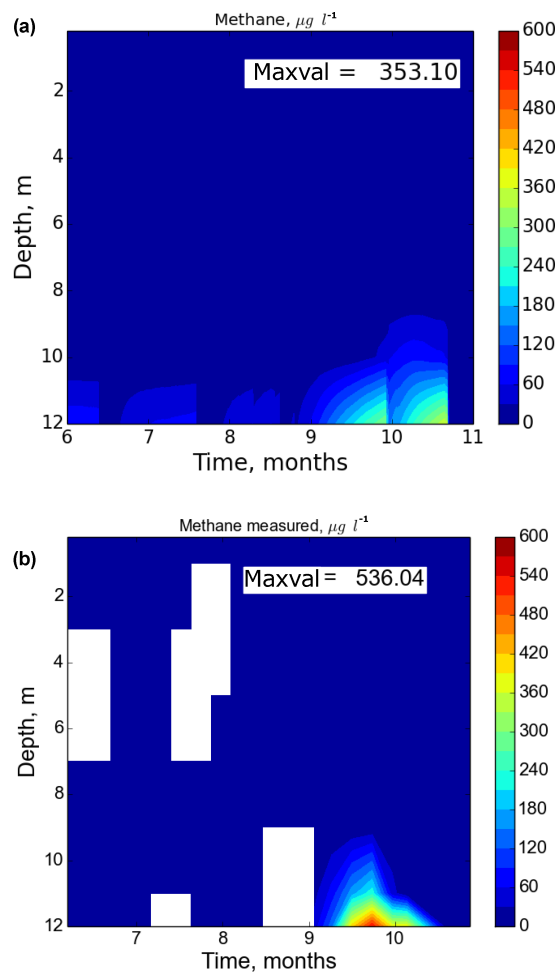

Figure 9. Time-depth distribution of dissolved $\mathrm{CH}_{4}$ in Kuivajärvi Lake. Months at the horizontal axis are from 2013

\section{Discussion}

\subsection{Temperature}

\subsubsection{Overview of the model performance in temperature}

The three-layer stratification in the lake (epilimnion, metalimnion, hypolimnion) is well reproduced by the LAKE model. This is the most significant summertime feature impacting the distribution of all physical quantities in a lake as well as biogeochemical ones. In this situation, the applicability of a 1-D approach is facilitated by extremely stable stratification in the thermocline (in Kuivajärvi Lake, metalimnetic Brunt-Väisälä frequency exceeded $0.1 \mathrm{~s}^{-1}$ in midsummer), i.e. the typical feature of dimictic lakes compared to large and deep lakes and oceans. This stratification is a key dynamic factor to which other ones have to be compared. Specifically, the wind force impact, disturbing the lake's layered structure, is assessed via the Wedderburn number $(W)$ (Shintani et al., 2010) or lake number (Imberger and Patterson, 1989), while the significance of Coriolis force can be quantified by comparing Rossby deformation radius $\left(L_{R}\right)$ to a lake's size (Patterson et al., 1984). The two parameters, $W$ and $L_{\mathrm{R}}$, are plotted in Figs. 11 and 12 respectively. We see that during June-August $W$ generally fluctuates around 50 implying that thermocline vertical displacement by wind forcing is about $\sim 100$ times less than the mixed-layer depth. However, in May, end of October and on short periods of several days during summer $W$ approaches unity making possible upwelling at lake's margins, similar to what was reported for 2011 in Heiskanen et al. (2014). At least two of these episodes, namely these in mid-June and end of July, are concomitant to mixed-layer cooling (Fig. 5a), weakening the lake stratification.

Rossby deformation radius, $L_{\mathrm{R}}$, is similar or smaller than the lake length $(\approx 2600 \mathrm{~m})$ so that Coriolis force should significantly modify the currents here. Indeed, neglecting the Coriolis force from dynamic equations of the model drastically increased vertical mixing in our simulations (not shown), making the mixed-layer depth unrealistically large.

The surface temperature time series are realistically reproduced by the model. This result is achieved by both the high quality of atmospheric forcing (all atmospheric variables were measured over the lake surface) and the properties of the model used. Surface temperature is defined by net heat stored in the mixed layer and the mixed-layer depth; i.e. the depth over which this heat is distributed. Hence, the parameterization of sensible and latent heat fluxes (the only unknowns in the net heat when radiation fluxes are measured), and momentum flux (the primary source for TKE production in the mixed layer) are critical for calculating surface temperature correctly. Serious concerns on the validity of Monin-Obukhov similarity theory for the case of a lake surrounded by bluff topography have been reported in the literature (e.g. see reasoning based on results of largeeddy simulation (LES) (Glazunov and Stepanenko, 2015) or laboratory experiments (Markfort et al., 2013)). However, it turns out that in the practice of 1-D lake model applications to such lakes not only Monin-Obukhov is the most physically based option in these models for obtaining surface heat fluxes so far, but also it still delivers acceptable accuracy for calculated surface temperature at seasonal timescales (Stepanenko et al., 2014; Heiskanen et al., 2015). As to momentum flux, it has been shown to be a crucial parameter regulating the rate of mixed-layer deepening during summer (see e.g. Stepanenko et al., 2014). This resulted in a widespread modelling practice where the drag coefficient, defining momentum flux at a given wind speed, has become a tunable parameter in $k-\epsilon$-based lake models. In our simulations, we do not calibrate the surface drag coefficient, but include a simple parameterization of momentum flux partitioning between waves and currents (Stepanenko et al., 2014), leading to a reduction of mixed-layer depth towards observed values (not shown).

\subsubsection{Internal seiches}

Consider now in more detail temperature fluctuations in the thermocline, not reproduced by the model (cf. Fig. 5a and b). Measured time series of temperature demonstrate that these fluctuations appear below the base of the mixed layer, 
where diurnal temperature variability diminishes. Thus, they are caused by neither the diurnal cycle of surface net heat nor by shortwave radiation absorption in the water column. Their occurrence throughout a thick (about $4 \mathrm{~m}$ ) layer of stable stratification, with Richardson number, $R i \gg 1$ (according to model results), where the vertical eddy conductivity should be largely suppressed, hints at the only feasible mechanism of these temperature changes that is due to (organized) vertical advection. Thence, the periodic character of these fluctuations implies flow oscillations, i.e. internal waves.

Figure 13 shows the Fourier spectrum of temperature time series at three depths in the thermocline. At all depths there are two distinct maxima at frequencies: $\omega \approx 8.5 \times 10^{-5} \mathrm{~s}^{-1}$ $\left(T_{\text {seiche }} \approx 20.5 \mathrm{~h}\right)$ and $\omega \approx 4.5 \times 10^{-4} \mathrm{~s}^{-1}\left(T_{\text {seiche }} \approx 3.9 \mathrm{~h}\right)$. The harmonic of $T_{\text {seiche }} \approx 20.5 \mathrm{~h}$ contains much more energy than that of $T_{\text {seiche }} \approx 3.9 \mathrm{~h}$. In order to interpret these spectra we use the method for seiche period calculation proposed by Münnich et al. (1992).

Starting from 2-D linearized incompressible Boussinesq equations and seeking the solution for vertical velocity, $w$, in a wave-like form:

$w(x, z, t)=W(z) \exp [i(k x-\omega t)]$,

where the rigid lid condition $\left.w\right|_{z=0, h}=0$ leads to an ordinary differential equation for the amplitude, $W$ :

$\frac{\mathrm{d}^{2} W}{\mathrm{~d} z^{2}}+\left(\frac{N^{2}}{\omega^{2}}-1\right) k^{2} W=0$,

$\left.W\right|_{z=0, h}=0$,

which is a Sturm-Liouville problem for frequencies, $\omega$ and corresponding eigenfunctions, $W$. We solved it with a shooting method with squared Brunt-Väisälä frequency $N^{2}$ taken from the mean temperature profile measured in July and $h=12.5 \mathrm{~m}$ (a depth of lake in the point of measurements). Considering first horizontal mode, $k=\pi / L_{x 0}$, we have $T_{\text {seiche, } 1}=6.5 \mathrm{~h}$ with $W$ having a form of the first vertical mode, usually denoted as V1H1 (one maximum of $W$ between $z=0$ and $z=h$ ) and $T_{\text {seiche, } 2}=21.2 \mathrm{~h}$ for the second vertical mode (one maximum of $W$ and one minimum, $\mathrm{V} 2 \mathrm{H} 1$ ). These frequencies correspond to those of maxima at the temperature spectrum (Fig. 13). The discrepancy between measured and calculated frequencies that are especially noticeable for $\mathrm{V} 1 \mathrm{H} 1$ mode ( $3.9 \mathrm{~h}$ vs. $6.5 \mathrm{~h}$ respectively) is expected, since the linear analysis described above neglects morphometry of the lake's bed (Fricker and Nepf, 2000), effects of Coriolis force and the complex temporal behaviour of the actual wind forcing.

The prominence of V2H1 mode in the temperature spectrum is what Münnich et al. (1992) found for an Alpine lake as well. A plausible explanation for that is the resonance between V2H1 seiche and the wind speed, both having close to diurnal periodicity (Mortimer, 1953).
Thus, the main conclusion of this section is a presence of significant internal seiches in Kuivajärvi Lake that may be responsible for additional mixing in the thermocline either in the interior of the lake or at its margins. This will be discussed in the following section (Sect. 5.2).

\subsection{Turbulent quantities}

In this section we will focus on turbulence characteristics in the thermocline and hypolimnion as they are factors for vertical transport of gases originating at a lake bottom. Moreover, the presence of seiches in the lake suggests additional mixing mechanisms to exist in the thermocline, such as production of TKE by near-bottom shear (Goudsmit, 2002) and breaking of internal waves at the sloping bed (MacIntyre et al., 2009; Boegman et al., 2005).

\subsubsection{TKE production terms}

The vertical distribution of TKE shown at Fig. 6 is formed as a result of an approximate balance between terms in the right-hand side of TKE Eq. (B1). Mean vertical distribution of TKE production by shear, $S$, by buoyancy, $B$ and by seiches, $S_{\text {seiche }}$ (only when Goudsmit parameterization is used, "IS+" experiment) in July is shown in Fig. 14.

First, we see that mean buoyancy production is positive in the top half of mixed layer $\left(\sim 10^{-9} / 10^{-7} \mathrm{~m}^{2} \mathrm{~s}^{-3}\right)$, indicating that nocturnal buoyancy production of TKE in this region overrides the daytime sink. It is several times (up to an order of magnitude) less than the shear production, however, exceeds the 3-5 orders of magnitude generation of TKE by seiches. Different experiments show almost identical profiles of $B$. This is because both the Goudsmit and Mellor parameterizations depend on $N$ providing a zero contribution to TKE and other turbulent quantities at $N=0$, and $N \approx 0$ in the mixed layer. Below, buoyancy production becomes negative due to stable stratification.

Vertical shear production is the largest contributor to TKE throughout a lake profile excepting thermocline, at $\sim 7 \mathrm{~m}$ depth, where it attains its minimum and becomes

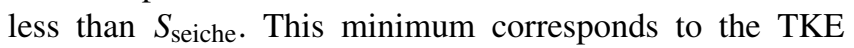
minimum (Fig. 6) and a minimum of eddy viscosity, v, approaching minimal value, $v_{\min }$. As in the model we do not use any "background diffusivity/viscosity/conductivity", the minimum value of $v$ and $v_{T}$ is set to a very small number, $v_{\min }=v_{T, \min }=10^{-8} \mathrm{~m}^{2} \mathrm{~s}^{-1}$ (cf. molecular viscosity at $10^{\circ} \mathrm{C}, v_{\mathrm{m}}=1.307 \times 10^{-6} \mathrm{~m}^{2} \mathrm{~s}^{-1}$ and heat diffusivity, $\left.v_{T, \mathrm{~m}}=1.41 \times 10^{-7} \mathrm{~m}^{2} \mathrm{~s}^{-1}\right)$. Hence, $S=v\left[(\partial u / \partial z)^{2}+\right.$ $\left.(\partial v / \partial z)^{2}\right]$ reaches negligible values, as $v=v_{\text {min }}$. Below thermocline, there is drastic difference in $S$ between experiments where the dynamic barotropic pressure gradient was taken into account (baseline experiment), and those without surface seiches - labelled by "SS-" on Fig. 14. The reason is that due to water surface inclination, currents are generated in hypolimnion, while stratification is not strong enough 


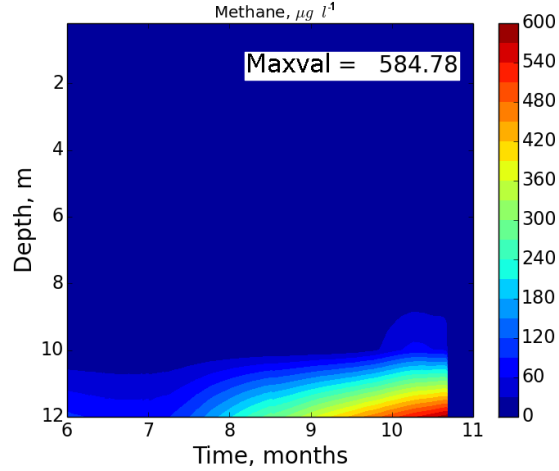

Figure 10. Time-depth distribution of dissolved $\mathrm{CH}_{4}$ in Kuivajärvi Lake. Months at the horizontal axis are from 2013. The model is run with surface seiches switched off ( $\mathrm{SS}-$ ).

to dominate over shear $(R i<0.25$, not shown). The largest shear production takes place in the experiment with both the Mellor parameterization and dynamic pressure gradient included ("GV+"). The value of $S$ is especially increased in the thermocline, because $N^{2}$ reaches a maximum there, and it contributes to corresponding additional shear proportionally. TKE also achieves maximal values for this experiment at all depths (Fig. 6). Still, heat conductance and diffusivity in the metalimnion are close to molecular values even in this case.

Additional shear production due to seiches attains a maximum in the thermocline with minima in the epilimnion and hypolimnion. This is again due to the proportionality $S_{\text {seiche }} \propto N^{2}$. The contribution of $S_{\text {seiche }}$ to TKE production remains minor compared to shear everywhere, excepting a small region in the thermocline, where TKE generation by vertical shear plunges to a minimum, as discussed above.

The strong effect of surface seiches on under-thermocline turbulence obtained in our study is yet to be verified with more complicated models (i.e. 3-D Reynolds-averaged Navier-Stokes or LES) and extensive turbulence measurements for Kuivajärvi Lake. Indeed, surface seiches are barotropic motions, not taking into account density stratification in a lake. As a consequence, their period of $\sim 1 \mathrm{~min}$ for Kuivajärvi Lake is orders of magnitude less than that of the V1H1 mode $(6.5 \mathrm{~h})$ and higher modes obtained from eigenvalue problem for continuous stratification (Sect. 5.1). Taking into account internal seiches in the model would drastically change frequencies of near-bottom current oscillations compared to surface seiches and thereby the hypolimnetic shear production of TKE. However, so far, to the best of our knowledge, internal seiche parameterization producing extra mixing in the hypolimnion has not been developed, as the pioneering attempt by Goudsmit (2002) introduced $S_{\text {seiche }} \propto N^{2}$ negligible in hypolimnion. Envisaging implementation of internal motions in the model for our future work we, however, note that introducing surface seiches allowed for the generation of TKE below thermocline quali- tatively consistent with a bulk of observational data (Wüest et al., 2000; Wüest and Lorke, 2003), demonstrating that summer stratification in dimictic lakes is comprised of two turbulent layers disconnected by quasi-laminar thermocline.

\subsubsection{Stationary Richardson number}

Stationary Richardson number, $R i_{\mathrm{st}}$, has been used in a number of studies (Burchard, 2002, and references therein), to characterize maximum stability under which the $k-\epsilon$ still model does not decrease TKE. Formally, it is a value of $R i$ derived from the $k-\epsilon$ model under homogeneous and stationary conditions. For the standard $k-\epsilon$ model, it takes the form

$R i_{\mathrm{st}}=\frac{N^{2}}{M^{2}}=\operatorname{Pr} \frac{\Delta c_{\epsilon 21}}{\Delta c_{\epsilon 23}}$,

where $M^{2}=\left[(\partial u / \partial z)^{2}+(\partial v / \partial z)^{2}\right]$ is a shear frequency squared, $P r$ is the turbulent Prandtl number, $\Delta c_{\epsilon 21}=c_{\epsilon 2}-$ $c_{\epsilon 1}$ and $\Delta c_{\epsilon 23}=c_{\epsilon 2}-c_{\epsilon 3}$, with the constants $c_{\epsilon 1}=1.44$ $c_{\epsilon 2}=1.92$ and $c_{\epsilon 3}$ is switched between two values depending on stratification, $c_{\epsilon 3}=0.5 \cdot[1-\mathrm{H}(B)] \cdot(-0.4)+0.5 \cdot[1+$ $\mathrm{H}(B)] \cdot 1.14$, where $\mathrm{H}()-$ Heaviside function, ensuring $c_{\epsilon 3}=$ -0.4 in stable stratification and $R i_{\mathrm{st}}=0.25$.

Introducing additional shear by gravity waves into the total shear (Mellor, 1989), $S=v\left(M^{2}+\alpha_{g} N^{2}\right)$, in both TKE and $\epsilon$ equations, doing analogous algebra as for Eq. (34), leads to a modification of the stationary Richardson number:

$R i_{\mathrm{st}}=\operatorname{Pr} \frac{\Delta c_{\epsilon 21}}{\Delta c_{\epsilon 23}-\alpha_{g} \operatorname{Pr} \Delta c_{\epsilon 21}}$,

yielding, with $\alpha_{g} \approx 0.7$ (Mellor, 1989), an increased estimate, $R i_{\mathrm{st}}=0.32$.

On the other side, when the $k-\epsilon$ model is supplemented by Goudsmit internal seiche parameterization (Goudsmit, 2002), i.e. when the shear production is modified as $S^{*}=$ $S+S_{\text {seiche, }} S=v M^{2}$, an expression for stationary Richardson number may be derived as well (see Appendix D):

$R i_{\mathrm{st}}=\frac{\operatorname{Pr} \Delta c_{\epsilon 21}}{\Delta c_{\epsilon 23}-v_{0}^{-1} \operatorname{Pr} C_{s} \Delta c_{\epsilon 21}\left(u_{a}^{2}+v_{a}^{2}\right)^{3 / 2}}$,

where $\left(u_{a}, v_{a}\right)$ stands for wind vector in the surface layer, $\nu_{0}$ - eddy viscosity at stationary turbulence regime, $C_{s}$ constant for a given lake including empirical parameters and lake morphometry characteristics. As there are no unique values for $k, \epsilon$ and $\nu_{0}$ resulting from uniformity and stationarity conditions, we assume a small value for $\nu_{0} \approx v_{\mathrm{m}}$ leading to an upper estimate, $R i_{\mathrm{st}}=0.30$. Larger values of $\nu_{0}$, according to Eq. (36), would decrease $R i_{\mathrm{st}}$.

Estimates provided above suggest that $R i_{\mathrm{st}}$ in the $k-\epsilon$ model still remains under unity, when gravity waves and 


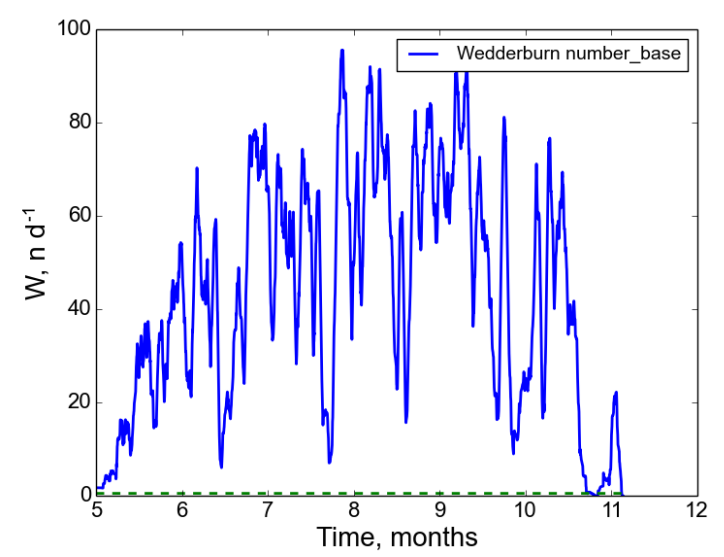

Figure 11. Time series of Wedderburn number from the model reference run. Months at the horizontal axis are from 2013. Dashed green line denotes critical value $\mathrm{W}_{\mathrm{cr}}=0.5$

internal seiche parameterizations are included. Thus, they cannot generate significant turbulence in the thermocline of Kuivajärvi Lake, where $\mathrm{Ri} \gg 1$. Indeed, in all experiments minimal eddy diffusivity in the thermocline was close to the minimal possible one set in the code, $10^{-8} \mathrm{~m}^{2} \mathrm{~s}^{-1}$, implying only molecular diffusion to perform vertical transport. Still, we envisage a possibility of mixing mechanisms raising total diffusivity above molecular levels in the metalimnion, given empirical evidences (e.g. Saggio and Imberger, 2001) and the fact that Mellor and Goudsmit parameterizations have not been tested thoroughly vs. extensive measurement data and/or LES (large eddy simulation) and DNS (Direct NavierStokes) simulation so far. Therefore, we conducted a sensitivity test on the influence of artificially increased diffusivity in the thermocline on gas concentrations ("MD" experiment, see next Sect. 5.3).

\subsection{Oxygen, methane and carbon dioxide}

As we see in Fig. $7 \mathrm{a}$ and $\mathrm{b}$, the $\mathrm{O}_{2}$ concentration is high in the beginning of June not only in the mixed layer (8$9 \mathrm{mg} \mathrm{L}^{-1}$ ), where it is produced by photosynthesis, but beneath the mixed layer as well $\left(5-7 \mathrm{~m} \mathrm{~L}^{-1}\right)$. This is due to maximal $\mathrm{O}_{2}$ concentrations throughout a water column during the spring overturn in the beginning of May. Afterwards, $\mathrm{O}_{2}$ remains high in the mixed layer while it decreases to almost zero values in hypolimnion by August.

A conspicuous feature of $\mathrm{O}_{2}$ content modelled is its gradual decline in the mixed layer during the deepening of the latter throughout October, from $\approx 7 \mathrm{mg} \mathrm{L}^{-1}$ to $\approx 5 \mathrm{mg} \mathrm{L}^{-1}$, whereas observed values even increased up to $\approx 9 \mathrm{mg} \mathrm{L}^{-1}$. In the model, $\mathrm{O}_{2}$ production due to photosynthesis reduced by the beginning of autumn under a drop in photosynthetically active radiation, and mixed-layer deepening caused a dilution of the $\mathrm{O}_{2}$ amount over a larger volume, reducing concentration. As to a rationale for the $\mathrm{O}_{2}$ concentration rise in

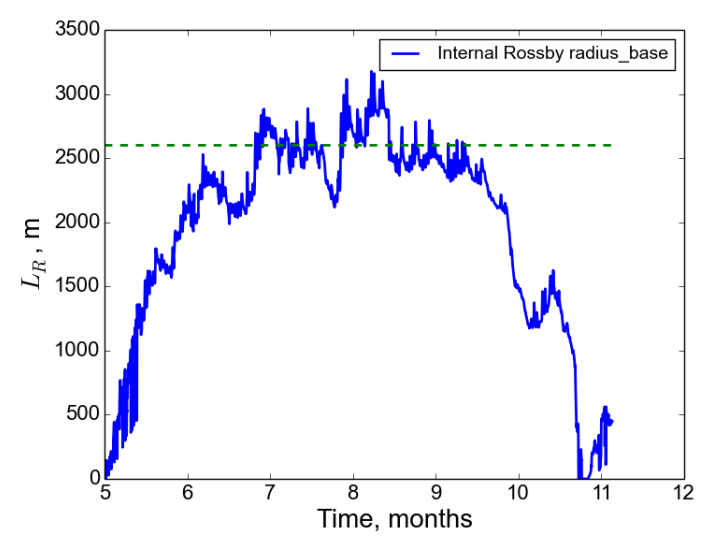

Figure 12. Time series of Rossby deformation radius from the model reference run. Months at the horizontal axis are from 2013. Dashed green line denotes the approximate Kuivajärvi Lake length, $2600 \mathrm{~m}$.

measurement data, we postpone it for future research. However, we can expect a change in phytoplankton communities when passing from summer stratification to autumnal mixing, and that these communities have different parameters for the photosynthesis-irradiance (P-I) curve. These effects have not been included in the model so far.

The process of $\mathrm{O}_{2}$ depletion in hypolimnion occurs differently in nature and in the model: in the model the rate of $\mathrm{O}_{2}$ depletion increases with depth, causing significant vertical concentration gradients, while in the measured field there is almost homogeneous distribution over depth; i.e. the rate of $\mathrm{O}_{2}$ decrease is near constant with depth. This discrepancy may be due to the misrepresentation in the model of two processes: vertical diffusion and biogeochemical oxygen consumption (sedimentary oxygen demand and biochemical oxygen demand).

In the model, BOD is distributed with depth according to temperature dependence only, so that it decreases towards the deepest point. In contrast, SOD, due to originating at lake margins, is represented as a marginal flux (see Sect. 2.1), i.e. being $\propto A^{-1} \mathrm{~d} A / \mathrm{d} z$. Hence, SOD rises to a maximum value as $A \rightarrow A_{h}, A_{h}=A(z=h)$. In hypolimnion, $\mathrm{BOD} \sim$ $10^{-9} \mathrm{~mol}\left(\mathrm{~m}^{3} \mathrm{~s}\right)^{-1}$ during summer months, while SOD $\sim$ $10^{-8} \mathrm{~mol}\left(\mathrm{~m}^{3} \mathrm{~s}\right)^{-1}$ increasing from $\approx 1 \times 10^{-8} \mathrm{~mol}\left(\mathrm{~m}^{3} \mathrm{~s}\right)^{-1}$ at the top of hypolimnion to $\approx 6 \times 10^{-8} \mathrm{~mol}\left(\mathrm{~m}^{3} \mathrm{~s}\right)^{-1}$ at its base. It is reasonable to expect the same morphometrical effect on SOD in nature, but it should be superimposed at SOD dependence on temperature and biogeochemical characteristics of sediments, which are depth dependent as well.

Unfortunately, so far, there is no observational data for Lake Kuivajärvi (e.g. turbulence measurements or any sediments data), facilitating one to discern whether it is enhanced turbulence below thermocline and/or nearly homogeneous SOD distribution with depth that makes measured $\mathrm{O}_{2}$ profiles much more even than these in the model. 
Consistently, the same questions arise considering $\mathrm{CO}_{2}$ distribution (Fig. 8a and b). Neglecting the spot of low $\mathrm{CO}_{2}$ hypolimnetic levels in the measured pattern around midAugust, which might be due to measurement errors, we see larger uniformity in the measured vertical distribution than in that calculated. Bottom concentration rises much faster in the model up to $\approx 16 \mathrm{mg} \mathrm{L}^{-1}$ by mid-August, whereas in the observed field this level is attained by mid-September only. This fast bottom accumulation of calculated $\mathrm{CO}_{2}$ corresponds to a fast decrease of $\mathrm{O}_{2}$ (Fig. 7a). This corroborates our suggestion above that either vertically even SOD or vertical mixing (or both) are misrepresented in the model under thermocline, as these processes affect $\mathrm{CO}_{2}$ and $\mathrm{O}_{2}$ so that to homogenize hypolimnetic profiles of both gases.

We also note that an abrupt increase of deep $\mathrm{CO}_{2}$ concentration that took place according to measurements in September in the depth interval $8-12 \mathrm{~m}$ is absent in the model. We argue that this rise is unlikely to be caused by local aerobic decomposition of organic matter, as the $\mathrm{O}_{2}$ is depleted near bottom by this time, $<1 \mathrm{mgL}^{-1}$ (Fig. 7), and this amount is far from enough to contribute to $\mathrm{CO}_{2}$ jump by $5-7 \mathrm{mg} \mathrm{L}^{-1}$, given stoichiometric ratio or corresponding reactions $\mathrm{O}_{2}: \mathrm{CO}_{2} \sim 1$. Hence, we suppose this $\mathrm{CO}_{2}$ is advected to the point of measurements from catchment. Moreover, this early autumnal sharp increase of $\mathrm{CO}_{2}$ is likely to be a peculiarity of 2013; at least, in 2011 and 2012 rising $\mathrm{CO}_{2}$ hypolimnetic concentration was much more smooth (Miettinen et al., 2015).

Kuivajärvi Lake is a significant source of $\mathrm{CO}_{2}$ (Heiskanen et al., 2014; Miettinen et al., 2015; Mammarella et al., 2015), and significant underestimation of surface concentration by the model $\left(0.39 \mathrm{mg} \mathrm{L}^{-1}\right.$ vs. $2.80 \mathrm{mg} \mathrm{L}^{-1}$ measured) is a serious drawback of the model set-up. As $\mathrm{CO}_{2}$ in the mixed layer is affected by a large number of processes (BOD, SOD, respiration, photosynthesis, diffusion to the atmosphere), it seems for us difficult to disentangle this problem on a solid physical/biogeochemical basis in this study, and it should be a part of separate research.

As stated above, only two constants were calibrated in the model, i.e. $P_{0}$ and $K_{\mathrm{CH}_{4} \text {,w }}$, which are responsible for magnitude of $\mathrm{CH}_{4}$ production in sediments and $\mathrm{CH}_{4}$ oxidation in water respectively. The value $P_{0}=3 \times 10^{-8} \mathrm{~mol}\left(\mathrm{~m}^{3} \mathrm{~s}\right)^{-1}$ chosen occurred to be very close to the value obtained for the thermokarst Shuchi Lake in north-eastern Siberia $\left(P_{0}=2.55 \times 10^{-8} \mathrm{~mol}\left(\mathrm{~m}^{3} \mathrm{~s}\right)^{-1}\right.$; see Stepanenko et al., 2011) and Seida Lake in northern European Russia $\left(P_{0}=4 \times\right.$ $10^{-8} \mathrm{~mol}\left(\mathrm{~m}^{3} \mathrm{~s}\right)^{-1}$; see Guseva et al., 2016). We note that it is not straightforward to compare these values, because the model version used in the Shuchi Lake study lacked such important features as taking into account bottom morphometry, bubbles dissolution in water, all biogeochemical processes involving $\mathrm{O}_{2}$ and $\mathrm{CO}_{2}$ but not $\mathrm{CH}_{4}$ oxidation. Nevertheless, the same order of magnitude of $P_{0}$ for three lakes of different genetic types with ecosystems functioning under drastically different climate conditions argues for robustness of our model formulation. A half-saturation constant for $\mathrm{CH}_{4}$, $K_{\mathrm{CH}_{4} \text {,w }}=3.75 \times 10^{-2} \mathrm{~mol} \mathrm{~m}^{-3}$, was set close to upper estimate of this parameter, found in literature (Martinez-Cruz et al., 2015).

Due to high $\mathrm{O}_{2}$ content, Kuivajärvi Lake is generally poor in $\mathrm{CH}_{4}$ (Miettinen et al., 2015). To better understand the reasons for low surface $\mathrm{CH}_{4}$ concentrations, it is instructive to scrutinize the budget of $\mathrm{CH}_{4}$ in the mixed layer (Fig. 15). We see that the $\mathrm{CH}_{4}$ fluxes nearly compensate each other, bubble fluxes being dominant in magnitude (see Table 3 ). The divergence of bubble flux is almost compensated by oxidation, whereas diffusion through thermocline is the smallest flux. Thus, in the model, the epilimnetic and hypolimnetic pools of $\mathrm{CH}_{4}$ are almost "disconnected" due to minimal TKE in metalimnion (see Sect. 5.2). Moreover, the total $\mathrm{CH}_{4}$ influx from shallow sediments is $\approx 6$ times larger than $\mathrm{CH}_{4}$ input by bubbles from deep sediments, i.e. those below the mixed layer (23.22 vs. $\left.4.63 \mathrm{mg}\left(\mathrm{m}^{2} \text { day }\right)^{-1}\right)$. This implies that shallow sediments are the main contributor of $\mathrm{CH}_{4}$ to the mixed layer so that surface $\mathrm{CH}_{4}$ concentration and eventually its diffusive flux to the atmosphere are controlled by $\mathrm{CH}_{4}$ production in shallow sediments and epilimnetic $\mathrm{O}_{2}$ amount (via oxidation). However, bubble $\mathrm{CH}_{4}$ flux from deep sediments is a considerable part of the total $\mathrm{CH}_{4}$ flux to the atmosphere, since in the model $68-70 \%$ of $\mathrm{CH}_{4}$ leaving sediments at a depth of $12.5 \mathrm{~m}$ in bubbles reaches the surface.

In the numerical experiment "SS-" with the LAKE model, where surface seiches (horizontal pressure gradient) were neglected, the seasonal pattern of $\mathrm{CH}_{4}$ concentration took the form presented at Fig. 10. In this case, the basal $\mathrm{CH}_{4}$ content began to rise about 2 months earlier than it was observed (Fig. 9b) and calculated in the reference run (Fig. 9a) and reached maximal value of $598.5 \mathrm{mg} \mathrm{L}^{-1}$ vs. $351.5 \mathrm{mg} \mathrm{L}^{-1}$ in the baseline experiment. This is caused by earlier $\mathrm{O}_{2}$ depletion (not shown) due to negligible $\mathrm{O}_{2}$ supply from above waters in conditions of very small TKE in hypolimnion (Fig. 6). Hence, we conclude that hypolimnetic turbulence is significant for gas accumulation and vertical distribution there, although it is likely to be of minor importance for mixed-layer concentrations of $\mathrm{O}_{2}, \mathrm{CO}_{2}$ and $\mathrm{CH}_{4}$, because of the small gas transfer through metalimnion (see Sect. 5.2).

The "SS-" experiment (Fig. 10) provides a clue for explanation of the saw-like pattern of $\mathrm{CH}_{4}$ concentration in the reference model run (Fig. 9a). The closer joint inspection of Figs. 7a and 9a reveals that $\mathrm{CH}_{4}$ drops near bottom coincide in time with $\mathrm{O}_{2}$ jumps. Oxygen jumps are evidently caused by enhanced vertical mixing, as there are no oxygen sources at large depths. In contrast, such mixing events are completely absent when surface seiches are switched off (Fig. 10). This leads us to the firm conclusion that the variability of mixing and respective gas concentration variations are caused by surface seiches intensified by increased wind forcing events. 


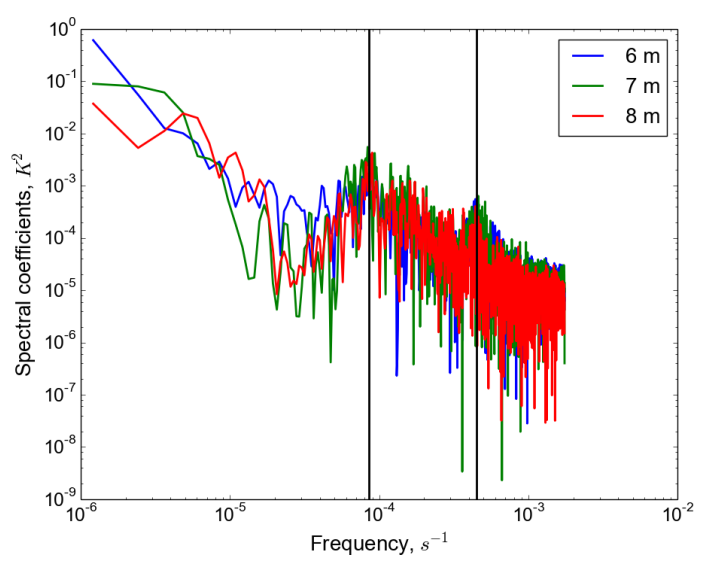

Figure 13. Fourier spectrum of water temperature fluctuations at depths 6,7 and $8 \mathrm{~m}$. Two vertical lines point at maxima corresponding to $\omega=8.5 \times 10^{-5} \mathrm{~s}^{-1}\left(T_{\text {seiche }} \approx 20.5 \mathrm{~h}\right)$, left, and $\omega=$ $4.5 \times 10^{-4} \mathrm{~s}^{-1}\left(T_{\text {seiche }} \approx 3.9 \mathrm{~h}\right)$, right

Finally, as the complete dissipation of turbulence under strong stratification is questioned by a number of lacustrine observational studies (Saggio and Imberger, 2001) and theoretical considerations (Zilitinkevich et al., 2012), we conducted a model run "MD" with increased minimal eddy viscosity, diffusivity and heat conductance, i.e. $v_{\min }=$ $v_{T, \min }=10^{-6} \mathrm{~m}^{2} \mathrm{~s}^{-1} \approx v_{\mathrm{m}} \approx 10 v_{T, \mathrm{~m}}$. This 10 times molecular diffusion through thermocline led to a drastic decrease in $\mathrm{CH}_{4}$ concentration below, so that the maximal bottom amount from June to October attained only $48.38 \mu \mathrm{g} \mathrm{L}^{-1}$ vs. $351.51 \mu \mathrm{g} \mathrm{L}^{-1}$ in a reference experiment. It was caused by enhanced downward diffusion of $\mathrm{O}_{2}$ from the mixed layer, consequently oxidizing $\mathrm{CH}_{4}$ diffused from sediments. Therefore, even suppressed turbulence may cause significant impact on hypolimnetic concentration of gases, having implications not only for greenhouse gases but also for anoxia events.

\section{Conclusions}

In this study a new version of the 1-D lake model LAKE is presented. It solves equations for temperature, momentum, turbulent kinetic energy and its dissipation rate, $\mathrm{O}_{2}$, $\mathrm{CO}_{2}$ and $\mathrm{CH}_{4}$ in a generic form derived from a horizontally averaged arbitrary prognostic variable. Heat and $\mathrm{CH}_{4}$ vertical transport are additionally realized in a set of vertical sediment columns that are coupled to a water body via continuity of flux and temperature (gas concentration). The fluxes of momentum, $\mathrm{O}_{2}$ and $\mathrm{CO}_{2}$ at the sloping bottom are described by appropriate formulations based on boundary layer laws and in-sediments biogeochemistry. The key biogeochemical transformations between $\mathrm{O}_{2}, \mathrm{CO}_{2}$ and $\mathrm{CH}_{4}$ in water are implemented. Both diffusive and ebullition flux of all gases are taken into account. Standard $k-\epsilon$ turbulence
Table 3. Mean for $\mathrm{CH}_{4}$ fluxes in/out of the lake mixed layer, $\mathrm{mg}\left(\mathrm{m}^{2} \text { day }\right)^{-1}$, normalized by lake surface area, MayOctober 2013. Positive terms are those transporting $\mathrm{CH}_{4}$ into the mixed layer.

\begin{tabular}{lr}
\hline Diffusion at the lake surface & -0.86 \\
Diffusion at the bottom of mixed layer & 0.09 \\
Diffusion plus ebullition from mixed-layer sediments & 23.22 \\
Ebullition at the bottom of mixed layer & 4.63 \\
Ebullition at the lake surface & -20.31 \\
Oxidation in the mixed layer & -7.41 \\
Residual (storage change) & -0.64 \\
\hline
\end{tabular}

closure is supplemented by parameterizations of internal seiches (Goudsmit, 2002), gravity waves (Mellor, 1989) and a new surface seiche formulation, developing the original concept by Svensson (1978).

The model is validated vs. extensive measurement data collected by University of Helsinki at Kuivajärvi Lake (southern Finland) (Miettinen et al., 2015; Mammarella et al., 2015) during the ice-free season of 2013 and including all meteorological variables above lake surface necessary to drive the model. In-water temperature, $\mathrm{O}_{2}, \mathrm{CO}_{2}$ and $\mathrm{CH}_{4}$ vertical profiles from the water column served to validate the model output.

The model was successful in capturing large-scale patterns of spatio-temporal variability of temperature and gases. Of all the model parameterizations, only two constants relevant to $\mathrm{CH}_{4}$ production and consumption were calibrated. The value of $P_{0}$, regulating $\mathrm{CH}_{4}$ production in sediments, occurred very close to these obtained in our previous studies of a thermokarst lake in north-eastern Siberia (Stepanenko et al., 2011) and of a subarctic lake in northern European Russia (Guseva et al., 2016), corroborating the robustness of the model used. It is uncertainty in a number of other parameters, responsible for reactions involving $\mathrm{O}_{2}$ and $\mathrm{CO}_{2}$, that is likely to contribute to model errors in hypolimnion and these of $\mathrm{CO}_{2}$ in the surface layer.

As both $\mathrm{CO}_{2}$ and $\mathrm{CH}_{4}$ typically accumulate below metalimnion in freshwater lakes (e.g. Bastviken et al., 2008), the vertical transport of these gases below mixed layer becomes an important factor for their evasion to the atmosphere. Our experiments together with stationary Richardson number analysis show that Mellor and Goudsmit extensions of $k-\epsilon$ model neither produce TKE in hypolimnion, nor generate turbulence in thermocline enough to sustain total diffusivity coefficient above molecular constant. However, surface seiche parameterization allowed one to produce turbulenceenhanced hypolimnion qualitatively consistent with empirical knowledge so far (Wüest et al., 2000; Wüest and Lorke, 2003). Reproducing considerable TKE in hypolimnion leads to much better correspondence of calculated $\mathrm{CH}_{4}$ to observed one. 


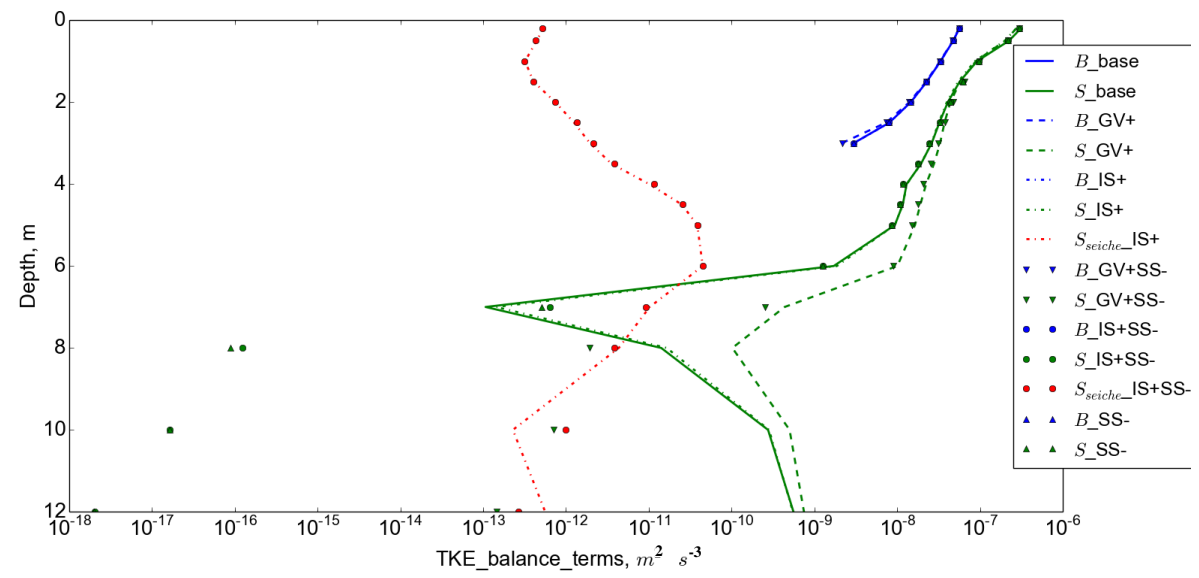

Figure 14. Mean TKE balance terms in Kuivajärvi Lake, July 2013, modelled. $B$ - production by buoyancy, $S$ - production by shear, $S_{\text {seiche }}$ - production by internal-seiche-induced shear. Model runs: "base" - baseline, "GV+" - including gravity waves shear parameterization (Gill, 1982; Mellor, 1989), "IS+" - including internal seiche mixing parameterization (Goudsmit, 2002), "GV+SS-" - the same as "GV+" but with surface seiches switched off, "IS+SS-" - the same as "IS+" but with surface seiches switched off, "SS-" - the same as "base"

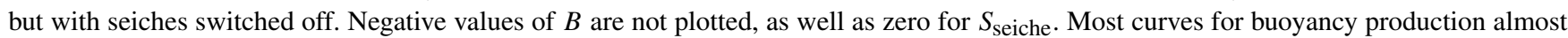
coincide.

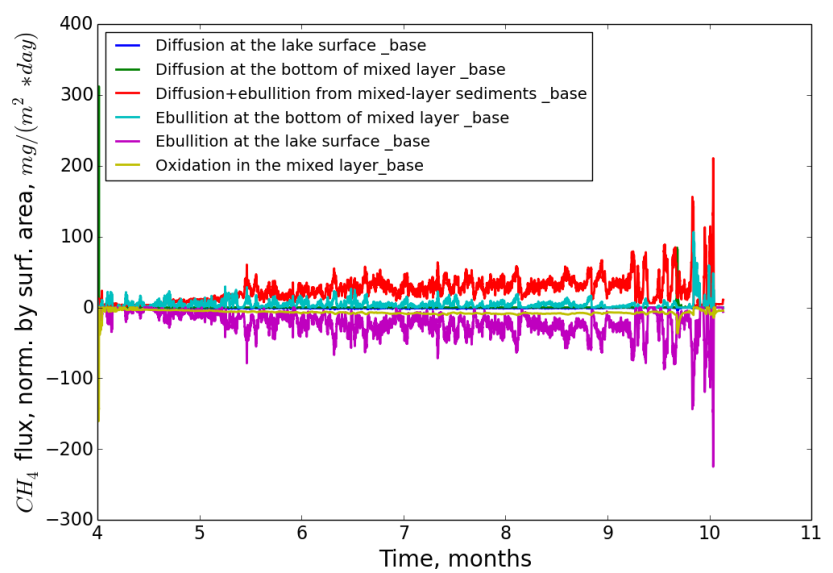

Figure 15. The components of $\mathrm{CH}_{4}$ balance in the surface mixed layer, normalized by lake surface area. Positive terms increase $\mathrm{CH}_{4}$ concentration in the mixed layer and negative ones are those decreasing $\mathrm{CH}_{4}$ content. Suffix “_base” means baseline experiment.

As there are strong doubts on complete suppression of turbulence even at $R i \gg 1$ (Saggio and Imberger, 2001; Zilitinkevich et al., 2012), we conducted an experiment with increased minimal diffusivity in thermocline, 10 times the molecular coefficient, causing a multifold decrease in nearbottom $\mathrm{CH}_{4}$ concentration. This points at thermocline turbulence as being a crucial bottleneck in quantifying greenhouse gas budget in lakes.
To conclude, we emphasize a role of internal lake oscillations and possible thermocline turbulence in vertical transfer of dissolved gases. These factors are omitted in the majority of lake models developed so far, and should be addressed carefully in their future formulations. This will allow one to get more rigorous regional and global estimates of greenhouse gases evasion to the atmosphere.

\section{Code availability}

The code for the LAKE 2.0 model is available on request from the author (Victor Stepanenko, stepanen@srcc.msu.ru, vstepanenkomeister@gmail.com). The code is supplied by Makefile to ease the compilation under Linux the technical documentation and users manual are provided in the model archive as well. 


\section{Appendix A: Equation for horizontally averaged quantity in a lake}

Consider Eq. (1) assuming $c=1$ for simplicity and an auxiliary operator:

$\widetilde{f}=\int_{A(z)} f \mathrm{~d} x \mathrm{~d} y$.

The cross section of a lake with notations used in this derivation is given at Fig. A1.

The integration operator Eq. (A1) possesses the following property:

$$
\begin{aligned}
& \frac{\partial \widetilde{f}}{\partial z}=\frac{\widetilde{\partial f}}{\partial z}+B_{f}, \\
& B_{f}=\int_{x_{1}(z)}^{x_{2}(z)}\left[\frac{\partial y_{2}}{\partial z} f\left(x, y_{2}, z\right)-\frac{\partial y_{1}}{\partial z} f\left(x, y_{1}, z\right)\right] \mathrm{d} x,
\end{aligned}
$$

stemming from the Leibnitz integral rule. Now apply operator $\overline{(\ldots)}$ to Eq. (1), insert $\bar{f}=A \widetilde{f}$, leading to

$$
\begin{aligned}
\frac{\partial A \bar{f}}{\partial t} & =-\int_{\Gamma_{A(z)}} f\left(\boldsymbol{u}_{h} \cdot \boldsymbol{n}\right) \mathrm{d} l-\int_{\Gamma_{A(z)}}\left(\boldsymbol{F}_{h} \cdot \boldsymbol{n}\right) \mathrm{d} l-\frac{\partial A \overline{w f}}{\partial z} \\
& -\frac{\partial A \overline{F_{z}}}{\partial z}+B_{w f}+B_{F_{z}}+A \overline{R_{f}},
\end{aligned}
$$

where we introduced $\boldsymbol{u}_{h}=\left\{u_{1}, u_{2}\right\}, \boldsymbol{F}_{h}=\left\{F_{1}, F_{2}\right\}$ and $\Gamma_{A(z)}$ is a boundary of $A$ at depth $z$. The first term to the right hand side of Eq. (A4) is a horizontal advection of property $f$ through boundaries of a water basin, i.e. the inflow from inlets, outflow by outlets and groundwater discharge. The second term represents non-advective horizontal fluxes at lake margins, whereas $B_{*}$ quantifies the effect of vertical fluxes at the lake bottom of depth $z$. Equation (A4) is the most general equation, which is, however, difficult to implement without further simplifications. First, assume that the lake bottom is quasi-horizontal, and in this case the rigid boundary condition for velocity brings $w \approx 0, B_{w f} \approx 0$. Then, we suppose that $\boldsymbol{F}=\left\{F_{1}, F_{2}, F_{3}\right\}$ is normal to the bottom boundary, which is a good approximation for diffusive transport, because it is proportional to a gradient of $f$, and this gradient is usually oriented almost perpendicular to the bottom surface. Therefore, $F_{1} \approx 0, F_{2} \approx 0$, vanishing the second term to the right-hand side of Eq. (A4). We also can decompose the vertical advection as $\overline{w f}=\bar{w} \bar{f}+\overline{w^{\prime} f^{\prime}}, w^{\prime}=w-\bar{w}, f^{\prime}=f-\bar{f}$. After these modifications, Eq. (A4) devolves to

$$
\frac{\partial A \bar{f}}{\partial t}=-\int_{\Gamma_{A(z)}} f\left(\boldsymbol{u}_{h} \cdot \boldsymbol{n}\right) \mathrm{d} l-\frac{\partial A \bar{w} \bar{f}}{\partial z}-\frac{\partial A \overline{w^{\prime} f^{\prime}}}{\partial z}
$$

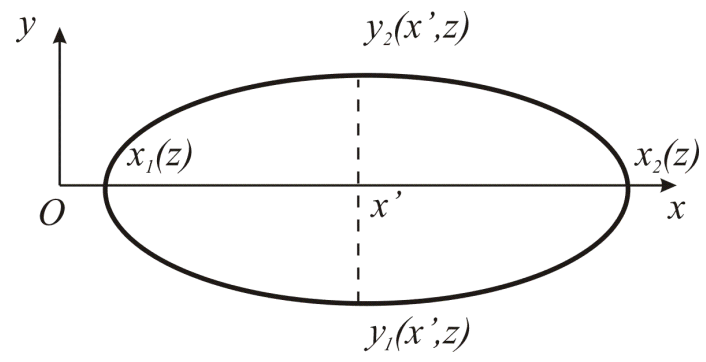

Figure A1. A lake horizontal cross section.

$$
-\frac{\partial A \overline{F_{z}}}{\partial z}+B_{F_{z}}+A \overline{R_{f}}
$$

At this stage it is timely to distinguish between turbulent and non-turbulent fluxes, namely $F_{z}=F_{\mathrm{t} z}+F_{\mathrm{n} z}$, and define "effective" turbulent flux, $\overline{F_{\mathrm{t} z}^{*}}=\overline{F_{\mathrm{t} z}}+\overline{w^{\prime} f^{\prime}}$. This effective turbulent flux includes horizontally averaged small-scale turbulent flux $\left(\overline{F_{\mathrm{tz}}}\right)$ and the flux mediated by large-scale flow structures, $\overline{w^{\prime} f^{\prime}}$. We also assume that the total non-advective flux $F_{z}$ at the bottom is the same at all bottom locations of the depth $z$, i.e. $\forall z: F_{z}(x, y)=$ const, $(x, y) \in \Gamma_{A(z)}$. Then, taking into account the above hypotheses and

$B_{1}=\int_{x_{1}(z)}^{x_{2}(z)}\left[\frac{\partial y_{2}}{\partial z}-\frac{\partial y_{1}}{\partial z}\right] \mathrm{d} x=\frac{\mathrm{d} A}{\mathrm{~d} z}$,

we transform Eq. (A5) to

$$
\begin{aligned}
\frac{\partial A \bar{f}}{\partial t} & =-\int_{\Gamma_{A(z)}} f\left(\boldsymbol{u}_{h} \cdot \boldsymbol{n}\right) \mathrm{d} l-\frac{\partial A \bar{w} \bar{f}}{\partial z}-\frac{\partial A \overline{F_{\mathrm{n} z}}}{\partial z} \\
& -\frac{\partial A \overline{F_{\mathrm{t} z}^{*}}}{\partial z}+\frac{\mathrm{d} A}{\mathrm{~d} z}\left(F_{\mathrm{n} z, \mathrm{~b}}(z)+F_{\mathrm{t} z, \mathrm{~b}}(z)\right)+A \overline{R_{f}},
\end{aligned}
$$

where $F_{*, \mathrm{~b}}(z)$ denote bottom values of fluxes at depth $z$. The mean vertical velocity, $w$, may be expressed from the horizontally integrated continuity Eq. (2):

$$
\frac{\partial A \bar{w}}{\partial z}=B_{w}-\int_{\Gamma_{A(z)}}\left(\boldsymbol{u}_{h} \cdot \boldsymbol{n}\right) \mathrm{d} l,
$$

where $B_{w} \approx 0$ according to the assumption of quasihorizontal bottom. This means, $w$ arises from disbalance between inflows and outflows and subsequent water level change. Since the LAKE model has not been applied for water bodies with significant water level change, the term with $w$ is omitted in Eq. (A7) in the model equation set. In order for Eq. (A7) equation to become tractable we use the following assumptions: 
- the "effective" turbulent flux may be represented via the gradient of mean quantity: $\overline{F_{\mathrm{t} z}^{*}}=-k_{f} \frac{\partial \bar{f}}{\partial z}$;

- the source averaged horizontally, $\overline{R_{f}(f, \ldots)}$, may be approximated as the same function of mean values, $\overline{R_{f}(f, \ldots)}=R_{f}(\bar{f}, \ldots)$.

Substituting these statements into Eq. (A7), we finally get

$$
\begin{aligned}
\frac{\partial \bar{f}}{\partial t} & =-\frac{1}{A} \int_{\Gamma_{A(z)}} f\left(\boldsymbol{u}_{h} \cdot \boldsymbol{n}\right) \mathrm{d} l+\frac{1}{A} \frac{\partial}{\partial z}\left(A k_{f} \frac{\partial \bar{f}}{\partial z}\right) \\
& -\frac{1}{A} \frac{\partial A \overline{F_{\mathrm{n} z}}}{\partial z}+\frac{1}{A} \frac{\mathrm{d} A}{\mathrm{~d} z}\left[F_{\mathrm{n} z, \mathrm{~b}}(z)+F_{\mathrm{t} z, \mathrm{~b}}(z)\right]+R_{f}(\bar{f}, \ldots) .
\end{aligned}
$$

\section{Appendix B: Standard $k-\epsilon$ model}

The prognostic equations for TKE, $k$ and its dissipation rate, $\epsilon$, take the form

$$
\begin{aligned}
\frac{\partial k}{\partial t} & =\frac{1}{A} \frac{\partial}{\partial z} A\left(v_{\mathrm{m}}+\frac{v}{\sigma_{k}}\right) \frac{\partial k}{\partial z}+S+B-\epsilon, \\
\frac{\partial \epsilon}{\partial t} & =\frac{1}{A} \frac{\partial}{\partial z} A\left(v_{\mathrm{m}}+\frac{v}{\sigma_{\epsilon}}\right) \frac{\partial \epsilon}{\partial z} \\
& +\frac{\epsilon}{k}\left(c_{\epsilon 1} S+c_{\epsilon 3} B-c_{\epsilon 2} \epsilon\right), \\
S & =v\left[\left(\frac{\partial u}{\partial z}\right)^{2}+\left(\frac{\partial v}{\partial z}\right)^{2}\right], \\
B & =-\frac{g}{\rho_{\mathrm{w} 0}} v_{T}\left(\alpha_{T} \frac{\partial T}{\partial z}+\alpha_{s} \frac{\partial s}{\partial z}\right), \\
v & =C_{e} \frac{k^{2}}{\epsilon} \\
v_{T} & =C_{e, T} \frac{k^{2}}{\epsilon} .
\end{aligned}
$$

Here, $\alpha_{T}(T, s)$ designates the thermal expansion coefficient and $\alpha_{s}(T, s)$ - expansion coefficient with respect to salinity, $s$. The coefficients and stability functions of the model are given in Table B1.

Boundary conditions are the same at the upper and lower boundaries, and exact for logarithmic boundary layer (Burchard and Petersen, 1999):

$$
\begin{aligned}
& \left.\frac{v}{\sigma_{k}} \frac{\partial k}{\partial z}\right|_{z=0, h}=0, \\
& \left.\frac{v}{\sigma_{\epsilon}} \frac{\partial \epsilon}{\partial z}\right|_{z=0, h}=-C_{e, 0}^{3 / 4} \frac{v}{\sigma_{\epsilon}} \frac{k^{3 / 2}}{\kappa z_{0}^{2}},
\end{aligned}
$$

where $C_{e, 0}=0.09$ designates a reference value for momentum stability function, $z_{0}=10^{-2} \mathrm{~m}-$ an empirical parameter, $\kappa=0.38-$ von Karman constant.
Table B1. Coefficients of standard $k-\epsilon$ model.

\begin{tabular}{ll}
\hline \multicolumn{2}{c}{ Constants } \\
\hline$\sigma_{k}$ & 1 \\
$\sigma_{\epsilon}$ & 1.111 \\
$c_{\epsilon 1}$ & 1.44 \\
$c_{\epsilon 2}$ & 1.92 \\
$c_{\epsilon 3}$ & 1.14 if $B>0,-0.4$ otherwise \\
\hline \multicolumn{2}{c}{ Stability functions } \\
\hline \multicolumn{2}{c}{ Stability function for momentum (Canuto et al., 2001) } \\
$C_{e}$ & Stability function for scalars (Canuto et al., 2001) \\
\hline
\end{tabular}

\section{Appendix C: Calibration of horizontal pressure gradient parameterization}

Consider fluctuations of surface level and a velocity of the flow that are homogeneous in $y$, developing in a channel of parallelepiped form, with depth $h$ and horizontal dimensions $L_{x}$ and $L_{y}$, neglecting friction and rotational effects. Under these conditions, momentum and mass conservation in a 1-D approximation takes the form

$$
\begin{aligned}
& \frac{\partial u}{\partial t}=-g \frac{\partial h}{\partial x}, \\
& g \frac{\partial h}{\partial x}=g \frac{h_{1}-h_{0}}{\alpha L_{x}}, \\
& \frac{\partial h_{1}}{\partial t}=-\frac{\partial h_{0}}{\partial t}=2 A^{-1} \bar{u}^{y z} h L_{y}=2 \bar{u}^{y z} h L_{x}^{-1},
\end{aligned}
$$

where $\alpha$ is a constant to be defined later, the operator $\bar{f}^{y z}$ averages the quantity $f$ in a plane $x=$ const, $A=L_{x} L_{y}$ is a horizontal cross section area of a channel, $h_{0}$ is an average surface level over a "left" part of the channel, $\left[0, L_{x} / 2\right] \times$ $\left[0, L_{y}\right]$, and $h_{1}$ is that for the right part, $\left[L_{x} / 2, L_{x}\right] \times\left[0, L_{y}\right]$. Approximation Eq. (C2) means that we confine ourselves to reproducing the first horizontal seiche mode, which is, however, often reported as the most prominent on lakes (Hutter et al., 2011). From Eq. (C1) we get

$\frac{\partial \bar{u}^{y z}}{\partial t}=-g \frac{\partial h}{\partial x}$.

Using Eqs. (C4), (C2) and (C3) yields:

$$
\begin{aligned}
\frac{\partial^{2} \bar{u}^{y z}}{\partial t^{2}} & =-\frac{\partial}{\partial t}\left(g \frac{\partial h}{\partial x}\right)=-\frac{g}{\alpha L_{x}} \frac{\partial}{\partial t}\left(h_{1}-h_{0}\right) \\
& =-\frac{4 g \bar{u}^{y z} h}{\alpha L_{x}^{2}} .
\end{aligned}
$$

Substituting here $\bar{u}^{y z} \sim \exp (-i \omega t)$, we get formulas for the frequency and period of surface seiche:

$\omega=\frac{2 \sqrt{g h}}{\sqrt{\alpha} L_{x}}, T=\frac{\pi \sqrt{\alpha} L_{x}}{\sqrt{g h}}$, 
and then, comparing to a Merian formula (Merian, 1828)

$T=\frac{2 L_{x}}{\sqrt{g h}}$,

gives

$\alpha=\frac{4}{\pi^{2}} \approx 0.41$

so that the value of $\alpha$ ensuring correct period of the first horizontal seiche mode significantly differs from a "natural" choice $\alpha=0.5$.

In the case of motions in both $x$ and $y$ directions, the formula, analogous to Eq. (C5) is valid for $y$ component of velocity, $v$. Equations for $u$ and $v$ are decoupled in this approximation, so that fluctuations of $u$ and $v$ develop independently. This is different from what we have in shallow water equations where $u$ and $v$ are coupled via divergence in mass continuity equation and corresponding surface elevation change. Hence, the first mode seiche model described above is yet to be generalized to a 2-D case in a way to include horizontal divergence. Still, for lacustrine environment applications, our approximation allows one to generate TKE below thermocline, which is principally unachievable in standard $k-\epsilon$ model.

\section{Appendix D: Stationary Richardson number for $k-\epsilon$ model with Goudsmit seiche parameterization}

An extension of standard $k-\epsilon$ model was proposed in (Goudsmit, 2002) to introduce additional TKE production by shear induced by internal seiches. The corresponding extra term, $S_{\text {seiche, }}$, has been added to production by mean vertical shear:

$S=v M^{2}+S_{\text {seiche }}$,

$S_{\text {seiche }}=-\frac{1-C_{\text {diss }} \sqrt{C_{\mathrm{d}, \mathrm{bot}}}}{\rho_{\mathrm{w} 0} c A_{\mathrm{b}}} \gamma \frac{1}{A} \frac{\mathrm{d} A}{\mathrm{~d} z} N^{2 q} E_{\text {seiche }}^{3 / 2}$,

where $C_{\mathrm{d} \text {,bot }} \approx 0.002$ is the bottom drag coefficient, $A_{\mathrm{b}}-$ the total bottom area, $c$ - normalizing constant, $\gamma-$ a coefficient, characterizing dissipation of seiche energy, $E_{\text {seiche }}$. The combination of $C_{\text {diss }} \sqrt{C_{\mathrm{d} \text {,bot }}} \approx 0.4\left(C_{\text {diss }}=10\right)$ is a fraction of seiche energy, transferred to heat in a viscous bottom sublayer. Hereafter, we will assume $q=1$ for simplicity. In Goudsmit (2002), this was a calibration parameter, taking values close to unity. From a stationarity condition in seiche energy equation (Eq. 15 in Goudsmit, 2002), we have a balance between energy transferred from wind drag work on a lake surface, and seiche dissipation:

$\alpha A_{0} \rho_{a} C_{\mathrm{d}}\left(u_{a}^{2}+v_{a}^{2}\right)^{3 / 2}=\gamma E_{\text {seiche }}^{3 / 2}$.
Here, $\alpha \approx 2 \times 10^{-3}$. Now we will use the $k-\epsilon$ model Eqs. (B1) and (B2) under stationarity and homogeneity conditions:

$S+B-\epsilon=0$,

$c_{\epsilon 1} S+c_{\epsilon 3} B-c_{\epsilon 2} \epsilon=0$.

Substituting Eq. (D3) into (D2), and then Eqs. (D1) to (D4) and (D5), eliminating $\epsilon$ from the latter two, we get

$$
\begin{array}{r}
-C_{e} \frac{k^{2}}{\epsilon} \Delta c_{\epsilon 21}+C_{e, T} \frac{k^{2}}{\epsilon} \Delta c_{\epsilon 23} R i_{s t} \\
-\Delta c_{\epsilon 21} C_{s} R i_{s t}\left(u_{a}^{2}+v_{a}^{2}\right)^{3 / 2}=0,
\end{array}
$$

where we defined a new value $C_{s}=$ $-\frac{\left(1-C_{\text {diss }} \sqrt{\left.C_{\mathrm{d}, \mathrm{bot}}\right)} A_{0} \rho_{a} C_{\mathrm{d}} \alpha\right.}{\rho_{\mathrm{w} 0} c A_{\mathrm{b}} A} \frac{\mathrm{d} A}{\mathrm{~d} z}>0$, which is a constant in time for a given lake. Then, assume that $C_{e} \frac{k^{2}}{\epsilon} \rightarrow v_{0}$ if $R i \rightarrow R i_{\mathrm{st}}$. The parameter $\nu_{0}$ is of arbitrary choice, however, we presume it to be a small value (e.g. $v_{0} \sim v_{\mathrm{m}}$ ), since it is eddy diffusivity on the edge of regime of decaying homogeneous turbulence. Thence,

$R i_{\mathrm{st}}=\frac{\operatorname{Pr} \Delta c_{\epsilon 21}}{\Delta c_{\epsilon 23}-v_{0}^{-1} \operatorname{Pr} C_{s} \Delta c_{\epsilon 21}\left(u^{2}+v^{2}\right)^{3 / 2}}$.

In the original work (Goudsmit, 2002), parameter $\alpha$ was calibrated to be $\sim 6 \times 10^{-3}$. After substituting typical values of parameters mentioned above and morphometry data of Kuivajärvi Lake, we got $R i_{\mathrm{st}}=0.30$. 


\section{Appendix E: List of symbols}

\section{E1 Thermodynamics and hydrodynamics}

$\lambda_{\mathrm{m}}=v_{T, \mathrm{~m}} c_{\mathrm{w}} \rho_{\mathrm{w} 0}, \mathrm{~J}(\mathrm{~m} \mathrm{~s} \mathrm{~K})^{-1}$

$\lambda_{\mathrm{t}}=v_{T} c_{\mathrm{w}} \rho_{\mathrm{w} 0}, \mathrm{~J}(\mathrm{~m} \mathrm{~s} \mathrm{~K})^{-1}$

$\Delta t, \mathrm{~s}$

$\Gamma_{A(z)}$

$\xi=z / h, \mathrm{n} / \mathrm{d}$

$\rho_{\mathrm{w} 0}=1000 \mathrm{~kg} \mathrm{~m}^{-3}$

$\epsilon, \mathrm{m}^{2} \mathrm{~s}^{-3}$

$\omega, \mathrm{s}^{-1}$

$A(z), \mathrm{m}^{3}$

$v, \mathrm{~m}^{2} \mathrm{~s}^{-1}$

$v_{\mathrm{m}}=1.307 \times 10^{-6} \mathrm{~m}^{2} \mathrm{~s}^{-1}$

$v_{T}, \mathrm{~m}^{2} \mathrm{~s}^{-1}$

$\nu_{T, \mathrm{~m}}=1.41 \times 10^{-7} \mathrm{~m}^{2} \mathrm{~s}^{-1}$

$B, \mathrm{~m}^{2} \mathrm{~s}^{-3}$

$B_{\mathrm{s}}, \mathrm{m} \mathrm{s}^{-1}$

$c_{\mathrm{W}}=3990 \mathrm{~J}(\mathrm{~kg} \mathrm{~K})^{-1}$

$\boldsymbol{F}=\left\{F_{1}, F_{2}, F_{3}\right\}=\left\{F_{x}, F_{y}, F_{z}\right\}$

$F_{\mathrm{n} z}$

$F_{\mathrm{t} z}$

$g, \mathrm{~m} \mathrm{~s}^{-2}$

$h, \mathrm{~m}$

$h_{\mathrm{s}}, \mathrm{m}$

$h_{\text {sed }}, \mathrm{m}$

$f$

$k, \mathrm{~m}^{2} \mathrm{~s}^{-2}$

$k_{f}, \mathrm{~m}^{2} \mathrm{~s}^{-1}$

$L_{x}, L_{y}, \mathrm{~m}$

$L_{\mathrm{R}}, \mathrm{m}$

$M, \mathrm{~s}^{-1}$

n

$N, \mathrm{~s}^{-1}$

$p, \mathrm{~Pa}$

$p_{\mathrm{a}}, \mathrm{Pa}$

$P r, \mathrm{n} / \mathrm{d}$

$R=8.314 \mathrm{~J}(\mathrm{~mol} \mathrm{~K})^{-1}$

$R_{f}$

$R i, \mathrm{n} / \mathrm{d}$

$S, \mathrm{~m}^{2} \mathrm{~s}^{-3}$

$S_{\mathrm{rad}}, \mathrm{W} \mathrm{m}^{-2}$

$t, \mathrm{~s}$

$T, \mathrm{~K}$

$T_{\mathrm{mp}}, \mathrm{K}$

$\boldsymbol{u}=\left\{u_{1}, u_{2}, u_{3}\right\}=\{u, v, w\}, \mathrm{ms}^{-1}$

$T_{\text {seiche, }} \mathrm{s}$

$\boldsymbol{u}_{h}=\left\{u_{1}, u_{2}\right\}=\{u, v\}, \mathrm{ms}^{-1}$

$\boldsymbol{u}_{a}=\left\{u_{a}, v_{a}\right\}, \mathrm{m} \mathrm{s}^{-1}$

$W, \mathrm{n} / \mathrm{d}$

$\boldsymbol{x}=\left\{x_{1}, x_{2}, x_{3}\right\}=\{x, y, z\}, \mathrm{m}$

$Z, \mathrm{~m}$

$z_{0 \mathrm{~b}, \mathrm{eff}}, \mathrm{m}$ molecular heat transfer (conductance) coefficient

turbulent heat transfer (conductance) coefficient

model time step

the boundary of a horizontal cross section of a lake at depth $z$

normalized vertical coordinate, pointed along gravity (n/d: non-dimensional)

reference water density

TKE dissipation rate

frequency

the area of horizontal cross section of a lake at depth $z$

turbulent viscosity in water

molecular viscosity of water

turbulent temperature transfer coefficient in water

molecular temperature transfer coefficient in water

buoyancy production/sink of TKE

precipitation minus evaporation at a lake surface

water specific heat

non-advective (turbulent and non-turbulent flux) a state variable $f$

non-turbulent vertical flux of a property $f$

turbulent vertical flux of a property $f$

acceleration of gravity

maximal lake depth

lake surface deviation from horizontal

the vertical size of sediment columns

arbitrary water state variable (velocity component, temperature, salinity, gas concentration, etc.)

turbulent kinetic energy (TKE)

turbulent diffusion/dissipation coefficient for variable $f$

horizontal sizes of lake's horizontal cross section $A(z)$ in $x$ and $y$ directions respectively

Rossby deformation radius

shear frequency

an outer normal unit vector

Brunt-Väisälä frequency

in-water pressure

atmospheric pressure

Prandtl number

universal gas constant

sum of sources and sinks of variable $f$

gradient Richardson number

shear production of TKE

shortwave radiation flux in water, positive downwards

time

temperature

melting point temperature

3 -D velocity vector in water

seiche period

horizontal velocity vector in water

wind speed vector

Wedderburn number

3-D position vector

vertical coordinate, originating at the bottom and pointing against gravity (used in the bubble model)

effective roughness length of a lake bottom 


\section{E2 Biogeochemistry}

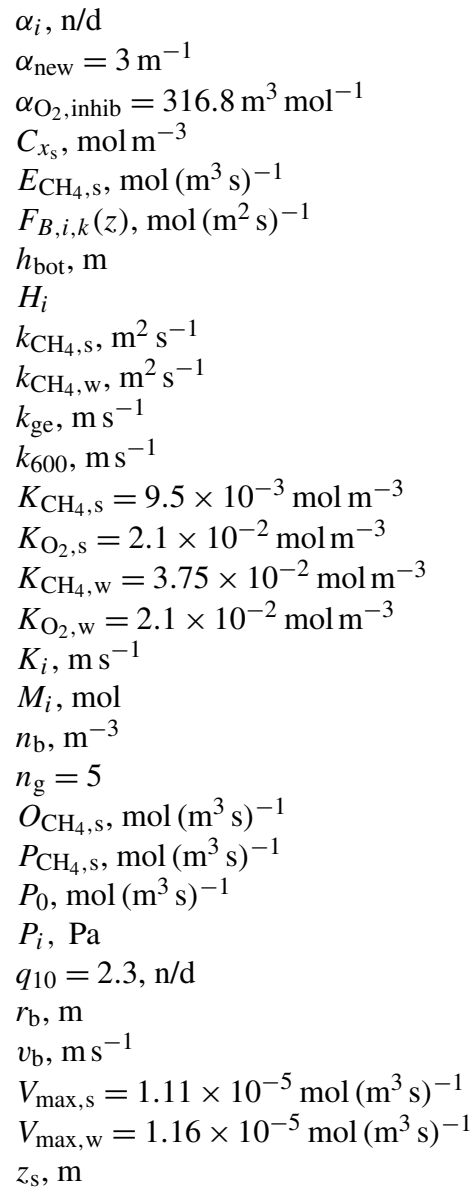

molar fraction of $i$ th gas in a bubble

a constant controlling the decrease of $\mathrm{CH}_{4}$ production with depth in sediments a constant controlling inhibition of $\mathrm{CH}_{4}$ production in sediments due to $\mathrm{O}_{2}$ presence bulk gas concentration in sediments, $x=\mathrm{CH}_{4}, \mathrm{O}_{2}$

$\mathrm{CH}_{4}$ sink in sediments due to ebullition

bubble flux of $i$ th gas from $k$ th column of sediments at depth $z$ the depth of a point at the bottom where the bubble is released the Henry's "constant" (temperature-dependent) of $i$ th gas molecular diffusivity of $\mathrm{CH}_{4}$ in sediments diffusion coefficient for $\mathrm{CH}_{4}$ in water gas exchange coefficient at the water-air interface ("piston velocity") piston velocity at $S c=600, S c$ - Schmidt number half-saturation constant with respect to $\mathrm{CH}_{4}$ for $\mathrm{CH}_{4}$ oxidation in sediments half-saturation constant with respect to $\mathrm{O}_{2}$ for $\mathrm{CH}_{4}$ oxidation in sediments half-saturation constant with respect to $\mathrm{CH}_{4}$ for $\mathrm{CH}_{4}$ oxidation in water half-saturation constant with respect to $\mathrm{O}_{2}$ for $\mathrm{CH}_{4}$ oxidation in water $i$ th gas exchange coefficient in a bubble

the content of $i$ th gas in a bubble number density of bubbles in water number of gases considered in a bubble aerobic $\mathrm{CH}_{4}$ oxidation rate in sediments production rate of $\mathrm{CH}_{4}$ in sediments empirical constant, an amplitude of production rate of $\mathrm{CH}_{4}$ in sediments, $P_{\mathrm{CH}_{4}, \mathrm{~s}}$ $i$ th gas pressure in a bubble temperature dependence constant for $\mathrm{CH}_{4}$ production in sediments bubble radius bubble vertical velocity $\mathrm{CH}_{4}$ oxidation potential in sediments $\mathrm{CH}_{4}$ oxidation potential in water depth in sediments, with respect to the sediments' column top 
Acknowledgements. This research is implemented in framework of Russian-Finnish collaboration, funded within CarLac (Academy of Finland, 1281196) and GHG-Lake projects. Russian co-authors are partially supported by grants of Russian Foundation of Basic Research (RFBR 14-05-91752, 15-35-20958). In addition, Academy of Finland Centre of Excellence (118780) and Academy Professor projects (1284701 and 1282842); ICOS (271878), ICOS-Finland (281255) and ICOS-ERIC (281250) and the Nordic Centre of Excellence - DEFROST are acknowledged.

Edited by: A. Ridgwell

\section{References}

Bastviken, D., Cole, J. J., Pace, M. L., and de Bogert, M. C.: Fates of methane from different lake habitats: Connecting wholelake budgets and $\mathrm{CH}_{4}$ emissions, J. Geophys. Res.-Biogeo., 113, G02024, doi:10.1029/2007JG000608, 2008.

Bastviken, D., Tranvik, L. J., Downing, J. A., Crill, P. M., and Enrich-Prast, A.: Freshwater Methane Emissions Offset the Continental Carbon Sink, Science, 331, 50 pp., doi:10.1126/science.1196808, 2011.

Beljaars, A. C. M. and Holtslag, A. A. M.: Flux Parameterization over Land Surfaces for Atmospheric Models, J. Appl. Meteorol., 30, 327-341, doi:10.1175/15200450(1991)030<0327:FPOLSF>2.0.CO;2, 1991.

Blees, J., Niemann, H., Erne, M., Zopfi, J., Schubert, C. J., and Lehmann, M. F.: Spatial variations in surface water methane super-saturation and emission in Lake Lugano, southern Switzerland, Aquat. Sci., 77, 535-545, doi:10.1007/s00027-015-0401-z, 2015

Boegman, L., Ivey, G. N., and Imberger, J.: The degeneration of internal waves in lakes with sloping topography, Limnol. Oceanogr., 50, 1620-1637, doi:10.4319/lo.2005.50.5.1620, 2005.

Borrel, G., Jézéquel, D., Biderre-Petit, C., Morel-Desrosiers, N., Morel, J.-P., Peyret, P., Fonty, G., and Lehours, A.-C.: Production and consumption of methane in freshwater lake ecosystems, Res. Microbiol., 162, 832-47, doi:10.1016/j.resmic.2011.06.004, 2011.

Burchard, H.: Applied Turbulence Modelling in Marine Waters, Vol. 100 of Lecture Notes in Earth Sciences, Springer Berlin Heidelberg, Berlin, Heidelberg, doi:10.1007/3-540-45419-5, 2002.

Burchard, H. and Petersen, O.: Models of turbulence in the marine environment - a comparative study of two-equation turbulence models, J. Marine Syst., 21, 29-53, doi:10.1016/S09247963(99)00004-4, 1999.

Businger, J. A., Wyngaard, J. C., Izumi, Y., and Bradley, E. F.: Flux-Profile Relationships in the Atmospheric Surface Layer, J. Atmos. Sci., 28, 181-189, doi:10.1175/15200469(1971)028<0181:FPRITA>2.0.CO;2, 1971.

Canuto, V. M., Howard, A., Cheng, Y., and Dubovikov, M. S.: Ocean Turbulence. Part I: One-Point Closure Model - Momentum and Heat Vertical Diffusivities, J. Phys. Oceanogr., 31, 1413-1426, doi:10.1175/15200485(2001)031<1413:OTPIOP>2.0.CO;2, 2001.

Chubarenko, I.: Horizontal convection above underwater slopes, Terra Baltica, Kaliningrad, 2010 (in Russian).
Cole, J. J. and Caraco, N. F.: Atmospheric exchange of carbon dioxide in a low-wind oligotrophic lake measured by the addition of SF6, Limnol. Oceanogr., 43, 647-656, doi:10.4319/lo.1998.43.4.0647, 1998.

Côté, J. and Konrad, J.-M.: A generalized thermal conductivity model for soils and construction materials, Can. Geotech. J., 42, 443-458, doi:10.1139/t04-106, 2005.

Crank, J. and Nicolson, P.: A practical method for numerical evaluation of solutions of partial differential equations of the heat-conduction type, Adv. Comput. Math., 6, 207-226, doi:10.1007/BF02127704, 1996.

Damm, E., Helmke, E., Thoms, S., Schauer, U., Nöthig, E., Bakker, K., and Kiene, R. P.: Methane production in aerobic oligotrophic surface water in the central Arctic Ocean, Biogeosciences, 7 , 1099-1108, doi:10.5194/bg-7-1099-2010, 2010.

Donelan, M. A., Drennan, W. M., Saltzman, E. S., and Wanninkhof, R. (Eds.): Gas Transfer at Water Surfaces, Geophysical Monograph Series, American Geophysical Union, Washington, D.C., doi:10.1029/GM127, 2002.

Downing, J. A., Prairie, Y. T., Cole, J. J., Duarte, C. M., Tranvik, L. J., Striegl, R. G., McDowell, W. H., Kortelainen, P., Caraco, N. F., and Melack, J. M.: The global abundance and size distribution of lakes, ponds, and impoundments, Limnol. Oceanogr., 51, 2388-2397, doi:10.4319/lo.2006.51.5.2388, 2006.

Dutra, E., Stepanenko, V. M., Balsamo, G., Viterbo, P., Miranda, P. M. A., Mironov, D., and Schär, C.: An offline study of the impact of lakes on the performance of the ECMWF surface scheme, Boreal Environ. Res., 15, 100-112, 2010.

Eerola, K., Rontu, L., Kourzeneva, E., Pour, H. K., and Duguay, C.: Impact of partly ice-free Lake Ladoga on temperature and cloudiness in an anticyclonic winter situation - a case study using a limited area model, Tellus A, 66, 23929, doi:10.3402/tellusa.v66.23929, 2014.

Fricker, P. D. and Nepf, H. M.: Bathymetry, stratification, and internal seiche structure, J. Geophys. Res., 105, 14237, doi:10.1029/2000JC900060, 2000.

Gill, A.: Atmosphere-ocean dynamics, Academic Press, New York, London, Paris, San Diego, San Francisco, Sao Paulo, Sydney, Tokyo, Toronto, 1982.

Glazunov, A. and Stepanenko, V. M.: Large Eddy Simulation of Stratified Turbulent Flows over Heterogeneous Natural Landscapes, IZV Atmos. Ocean Phy., 51, 403-415, 2015.

Goudsmit, G.-H.: Application of $k-\epsilon$ turbulence models to enclosed basins: The role of internal seiches, J. Geophys. Res., 107 3230, doi:10.1029/2001JC000954, 2002.

Guseva, S., Stepanenko, V., Shurpali, N., Biasi, C., Marushchak, M., and Lind, S.: Numerical Simulation of Methane Emission from Subarctic Lake in Komi Republic, Russia, Geography, Environment, Sustainability, accepted, 2016.

Hari, P. and Kulmala, M.: Station for Measuring EcosystemAtmosphere Relations (SMEAR II), Boreal Environ. Res., 10, 315-322, 2005.

Heiskanen, J. J., Mammarella, I., Haapanala, S., Pumpanen, J., Vesala, T., MacIntyre, S., and Ojala, A.: Effects of cooling and internal wave motions on gas transfer coefficients in a boreal lake, Tellus B, 66, 22827, doi:10.3402/tellusb.v66.22827, 2014.

Heiskanen, J. J., Mammarella, I., Ojala, A., Stepanenko, V., Erkkilä, K.-M., Miettinen, H., Sandström, H., Eugster, W., Leppäranta, M., Järvinen, H., Vesala, T., and Nordbo, A.: Ef- 
fects of water clarity on lake stratification and lake-atmosphere heat exchange, J. Geophys. Res.-Atmos., 120, 7412-7428, doi:10.1002/2014JD022938, 2015.

Hostetler, S. W. and Bartlein, P. J.: Simulation of lake evaporation with application to modeling lake level variations of HarneyMalheur Lake, Oregon, Water Resour. Res., 26, 2603-2612, doi:10.1029/WR026i010p02603, 1990.

Hutter, K., Wang, Y., and Chubarenko, I. P.: Physics of Lakes. Volume 2: Lakes as Oscillators, Springer-Verlag, Berlin Heidelberg, 1st Edn., doi:10.1007/978-3-642-19112-1, 2011.

Huttunen, J. T., Väisänen, T. S., Hellsten, S. K., and Martikainen, P. J.: Methane fluxes at the sediment-water interface in some boreal lakes and reservoirs, Boreal Environ. Res., 11, 27-34, 2006.

Imberger, J. and Patterson, J. C.: Physical Limnology, Vol. 27 of Advances in Applied Mechanics, 303-475, Elsevier, doi:10.1016/S0065-2156(08)70199-6, 1989.

Jamialahmadi, M., Branch, C., and Müller-Steinhagen, J.: Terminal bubble rise velocity in liquids, Trans. Inst. Chem. Eng., 72, 119122, 1994.

Jöhnk, K. D.: 1D Hydrodynamische Modelle in der Limnophysik. Turbulenz - Meromixis - Sauerstoff, Tech. rep., Insitute of Limnophysics, University of Amsterdam, Amsterdam, 2001.

Jönhk, K. D., Huisman, J., Sharples, J., Sommeijer, B., Visser, P. M., and Stroom, J. M.: Summer heatwaves promote blooms of harmful cyanobacteria, Glob. Change Biol., 14, 495-512, doi:10.1111/j.1365-2486.2007.01510.x, 2008.

Juutinen, S., Rantakari, M., Kortelainen, P., Huttunen, J. T., Larmola, T., Alm, J., Silvola, J., and Martikainen, P. J.: Methane dynamics in different boreal lake types, Biogeosciences, 6, 209223, doi:10.5194/bg-6-209-2009, 2009.

Kessler, M. A., Plug, L. J., and Walter Anthony, K. M.: Simulating the decadal- to millennial-scale dynamics of morphology and sequestered carbon mobilization of two thermokarst lakes in NW Alaska, J. Geophys. Res.-Biogeo., 117, G00M06, doi:10.1029/2011JG001796, 2012.

Kirillin, G., Forrest, A., Graves, K., Fischer, A., Engelhardt, C., and Laval, B.: Axisymmetric circulation driven by marginal heating in ice-covered lakes, Geophys. Res. Lett., 42, 2893-2900, doi:10.1002/2014GL062180, 2015.

Lidstrom, M. E. and Somers, L.: Seasonal study of methane oxidation in lake washington, Appl. Environ. Microbiol., 47, 12551260, 1984.

Liikanen, A., Murtoniemi, T., Tanskanen, H., Väisänen, T., and Martikainen, P. J.: Effects of temperature and oxygen availability on greenhouse gas and nutrient dynamics in sediment of a eutrophic mid-boreal lake, Biogeochemistry, 59, 269-286, doi:10.1023/A:1016015526712, 2002.

Lofton, D. D., Whalen, S. C., and Hershey, A. E.: Effect of temperature on methane dynamics and evaluation of methane oxidation kinetics in shallow Arctic Alaskan lakes, Hydrobiologia, 721, 209-222, doi:10.1007/s10750-013-1663-x, 2013.

MacIntyre, S., Clark, J. F., Jellison, R., and Fram, J.: Turbulent mixing induced by nonlinear internal waves in Mono Lake, California, Limnol. Oceanogr., 54, 2255-2272, doi:10.4319/lo.2009.54.6.2255, 2009.

MacIntyre, S., Jonsson, A., Jansson, M., Aberg, J., Turney, D. E., and Miller, S. D.: Buoyancy flux, turbulence, and the gas transfer coefficient in a stratified lake, Geophys. Res. Lett., 37, L24604, doi:10.1029/2010GL044164, 2010.
Mammarella, I., Nordbo, A., Rannik, U., Haapanala, S., Levula, J., Laakso, H., Ojala, A., Peltola, O., Heiskanen, J., Pumpanen, J., and Vesala, T.: Carbon dioxide and energy fluxes over a small boreal lake in Southern Finland, J. Geophys. Res.-Biogeo., 120, 1296-1314, doi:10.1002/2014JG002873, 2015.

Markfort, C. D., Porté-Agel, F., and Stefan, H. G.: Canopy-wake dynamics and wind sheltering effects on Earth surface fluxes, Environ. Fluid Mech., 14, 663-697, doi:10.1007/s10652-013-9313-4, 2013.

Martinez-Cruz, K., Sepulveda-Jauregui, A., Walter Anthony, K., and Thalasso, F.: Geographic and seasonal variation of dissolved methane and aerobic methane oxidation in Alaskan lakes, Biogeosciences, 12, 4595-4606, doi:10.5194/bg-12-4595-2015, 2015.

Martynov, A., Sushama, L., Laprise, R., Winger, K., and Dugas, B.: Interactive lakes in the Canadian Regional Climate Model, version 5: the role of lakes in the regional climate of North America, Tellus A, 64, 16226, doi:10.3402/tellusa.v64i0.16226, 2012.

McGinnis, D., Greinert, J., Artemov, Y., Beaubien, S., and Wüest, A.: The fate of rising methane bubbles in stratified waters: what fraction reaches the atmosphere?, J. Geophys. Res., 111, C09007, doi:10.1029/2005JC003183, 2006.

Mellor, G. L.: Retrospect on oceanic boundary layer modeling and second moment closure, in: Parameterization of Small-Scale Processes; Proc. of the Aha Hulikoa Hawaiian Winter Workshop, edited by Müller, P. and Henderson, D., pp. 251-271, Univ. of Hawaii at Manoa, Honolulu, 1989.

Melton, J. R., Wania, R., Hodson, E. L., Poulter, B., Ringeval, B., Spahni, R., Bohn, T., Avis, C. A., Beerling, D. J., Chen, G., Eliseev, A. V., Denisov, S. N., Hopcroft, P. O., Lettenmaier, D. P., Riley, W. J., Singarayer, J. S., Subin, Z. M., Tian, H., Zürcher, S., Brovkin, V., van Bodegom, P. M., Kleinen, T., Yu, Z. C., and Kaplan, J. O.: Present state of global wetland extent and wetland methane modelling: conclusions from a model intercomparison project (WETCHIMP), Biogeosciences, 10, 753788, doi:10.5194/bg-10-753-2013, 2013.

Merian, J.: Ueber die Bewegung tropfbarer Flüssigkeiten in Gefässen [On the motion of drippable liquids in containers, $\mathrm{PhD}$ thesis, Basel, Schweighauser, 1828.

Miettinen, H., Pumpanen, J., Heiskanen, J. J., Aaltonen, H., Mammarella, I., Ojala, A., Levula, J., and Rantakari, M.: Towards a more comprehensive understanding of lacustrine greenhouse gas dynamics - two-year measurements of concentrations and fluxes of $\mathrm{CO}_{2}, \mathrm{CH}_{4}$ and $\mathrm{N}_{2} \mathrm{O}$ in a typical boreal lake surrounded by managed forests, Boreal Environ. Res., 20, 75-89, 2015.

Mironov, D., Heise, E., Kourzeneva, E., and Ritter, B.: Implementation of the lake parameterisation scheme FLake into the numerical weather prediction model COSMO, Boreal Environ. Res., 15, 218-230, 2010.

Mortimer, C. H.: The resonant response of stratified lakes to wind, Schweiz. Z. Hydrol., 15, 94-151, doi:10.1007/BF02486219, 1953.

Münnich, M., Wüest, A., and Imboden, D. M.: Observations of the second vertical mode of the internal seiche in an alpine lake, Limnol. Oceanogr., 37, 1705-1719, doi:10.4319/lo.1992.37.8.1705, 1992.

Nordbo, A., Launiainen, S., Mammarella, I., Leppäranta, M., Huotari, J., Ojala, A., and Vesala, T.: Long-term energy flux measurements and energy balance over a small boreal lake using eddy 
covariance technique, J. Geophys. Res.-Atmos., 116, D02119, doi:10.1029/2010JD014542, 2011.

Omstedt, A.: Guide to Process Based Modeling of Lakes and Coastal Seas, Springer-Verlag, Berlin Heidelberg, 2011.

Patterson, J. C., Hamblin, P. F., and Imberger, J.: Classification and dynamic simulation of the vertical density structure of lakes, Limnol. Oceanogr., 29, 845-861, doi:10.4319/lo.1984.29.4.0845, 1984.

Paulson, C. A.: The Mathematical Representation of Wind Speed and Temperature Profiles in the Unstable Atmospheric Surface Layer, J. Appl. Meteorol., 9, 857-861, doi:10.1175/15200450(1970)009<0857:TMROWS>2.0.CO;2, 1970.

Rontu, L., Eerola, K., Kourzeneva, E., and Vehviläinen, B.: Data assimilation and parametrisation of lakes in HIRLAM, Tellus A, 64, 17611, doi:10.3402/tellusa.v64i0.17611, 2012.

Saggio, A. and Imberger, J.: Mixing and turbulent fluxes in the metalimnion of a stratified lake, Limnol. Oceanogr., 46, 392-409, doi:10.4319/lo.2001.46.2.0392, 2001

Sander, R.: Henry's law constants, Tech. rep., available at: http:// www.henrys-law.org/henry-3.0.pdf (last access: 26 May 2016), 1999.

Scandella, B. P., Varadharajan, C., Hemond, H. F., Ruppel, C., and Juanes, R.: A conduit dilation model of methane venting from lake sediments, Geophys. Res. Lett., 38, L06408, doi:10.1029/2011GL046768, 2011.

Schilder, J., Bastviken, D., van Hardenbroek, M., Kankaala, P., Rinta, P., Stötter, T., and Heiri, O.: Spatial heterogeneity and lake morphology affect diffusive greenhouse gas emission estimates of lakes, Geophys. Res. Lett., 40, 5752-5756, doi:10.1002/2013GL057669, 2013.

Shintani, T., de la Fuente, A., Niño, Y., and Imberger, J.: Generalizations of the Wedderburn number: Parameterizing upwelling in stratified lakes, Limnol. Oceanogr., 55, 1377-1389, doi:10.4319/lo.2010.55.3.1377, 2010.

Stefan, H. G. and Fang, X.: Dissolved oxygen model for regional lake analysis, Ecol. Model., 71, 37-68, doi:10.1016/03043800(94)90075-2, 1994.

Stepanenko, V., Jöhnk, K., Machulskaya, E., Perroud, M., Subin, Z., Nordbo, A., Mammarella, I., and Mironov, D.: Simulation of surface energy fluxes and stratification of a small boreal lake by a set of one-dimensional models, Tellus A, 66, 21389, doi:10.3402/tellusa.v66.21389, 2014.

Stepanenko, V. M. and Lykossov, V. N.: Numerical modeling of heat and moisture transfer processes in a system lake-soil, Russ. Meteorol. Hydrol., 3, 95-104, 2005.

Stepanenko, V. M., Martynov, A., Goyette, S., Fang, X., Perroud, M., and Mironov, D.: First steps of a Lake Model Intercomparison Project, Boreal Environ. Res., 15, 191-202, 2010.

Stepanenko, V. M., Machul'skaya, E. E., Glagolev, M. V., and Lykossov, V. N.: Numerical modeling of methane emissions from lakes in the permafrost zone, Izvestiya, Atmos. Ocean. Phys., 47, 252-264, doi:10.1134/S0001433811020113, 2011.

Stepanenko, V. M., Martynov, A., Jöhnk, K. D., Subin, Z. M., Perroud, M., Fang, X., Beyrich, F., Mironov, D., and Goyette, S.: A one-dimensional model intercomparison study of thermal regime of a shallow, turbid midlatitude lake, Geosci. Model Dev., 6, 1337-1352, doi:10.5194/gmd-6-1337-2013, 2013.

Subin, Z. M., Murphy, L. N., Li, F., Bonfils, C., and Riley, W. J.: Boreal lakes moderate seasonal and diurnal temperature varia- tion and perturb atmospheric circulation: analyses in the Community Earth System Model 1 (CESM1), Tellus A, 64, 15639, doi:10.3402/tellusa.v64i0.15639, 2012.

Svensson, U.: A mathematical model of the seasonal thermocline, PhD Lund Inst. of Technol., 1978.

Tan, Z. and Zhuang, Q.: Arctic lakes are continuous methane sources to the atmosphere under warming conditions, Environ. Res. Lett., 10, 054016, doi:10.1088/1748-9326/10/5/054016, 2015a.

Tan, Z. and Zhuang, Q.: Arctic lakes are continuous methane sources to the atmosphere under warming conditions, Environ. Res. Lett., 10, 054016, doi:10.1088/1748-9326/10/5/054016, 2015b.

Tan, Z., Zhuang, Q., and Walter Anthony, K.: Modeling methane emissions from arctic lakes: Model development and site-level study, J. Adv. Model. Earth Syst., 7, 459-483, doi:10.1002/2014MS000344, 2015.

Tranvik, L. J., Downing, J. A., Cotner, J. B., Loiselle, S. A., Striegl, R. G., Ballatore, T. J., Dillon, P., Finlay, K., Fortino, K., Knoll, L. B., Kortelainen, P. L., Kutser, T., Larsen, S., Laurion, I., Leech, D. M., McCallister, S. L., McKnight, D. M., Melack, J. M., Overholt, E., Porter, J. A., Prairie, Y., Renwick, W. H., Roland, F., Sherman, B. S., Schindler, D. W., Sobek, S., Tremblay, A., Vanni, M. J., Verschoor, A. M., von Wachenfeldt, E., and Weyhenmeyer, G. A.: Lakes and reservoirs as regulators of carbon cycling and climate, Limnol. Oceanogr., 54, 2298-2314, doi:10.4319/lo.2009.54.6_part_2.2298, 2009.

Walker, R. R. and Snodgrass, W. J.: Model for Sediment Oxygen Demand in Lakes, J. Environ. Eng., 112, 25-43, doi:10.1061/(ASCE)0733-9372(1986)112:1(25), 1986.

Walter, B., Heimann, M., and Shannon, R.: A Process Based Model to Derive Methane Emissions from Natural Wetlands, Tech. rep., Max Planck Institut fur Meteorologie, Hamburg, 1996.

Walter, B. P. and Heimann, M.: A process-based, climate-sensitive model to derive methane emissions from natural wetlands: Application to five wetland sites, sensitivity to model parameters, and climate, Global Biogeochem. Cy., 14, 745-765, doi:10.1029/1999GB001204, 2000.

Wania, R., Ross, I., and Prentice, I. C.: Integrating peatlands and permafrost into a dynamic global vegetation model: 1. Evaluation and sensitivity of physical land surface processes, Global Biogeochem. Cy., 23, GB3014, doi:10.1029/2008GB003412, 2009.

Wüest, A. and Lorke, A.: SMALL-SCALE HYDRODYNAMICS IN LAKES, Annu. Rev. Fluid Mech., 35, 373-412, 2003.

Wüest, A., Piepke, G., and Van Senden, D. C.: Turbulent kinetic energy balance as a tool for estimating vertical diffusivity in wind-forced stratified waters, Limnol. Oceanogr., 45, 13881400, doi:10.4319/1o.2000.45.6.1388, 2000.

Yamamoto, A., Yamanaka, Y., and Tajika, E.: Modeling of methane bubbles released from large sea-floor area: Condition required for methane emission to the atmosphere, Earth Planet. Sc. Lett., 284, 590-598, doi:10.1016/j.epsl.2009.05.026, 2009.

Yvon-Durocher, G., Allen, A. P., Bastviken, D., Conrad, R., Gudasz, C., St-Pierre, A., Thanh-Duc, N., and del Giorgio, P. A.: Methane fluxes show consistent temperature dependence across microbial to ecosystem scales, Nature, 507, 488-491, doi:10.1038/nature13164, 2014. 
Zheng, L. and Yapa, P. D.: Modeling gas dissolution in deepwater oil/gas spills, J. Mar. Syst., 31, 299-309, 2002.

Zilitinkevich, S. S., Elperin, T., Kleeorin, N., Rogachevskii, I., and Esau, I.: A Hierarchy of Energy- and Flux-Budget (EFB) Turbulence Closure Models for Stably-Stratified Geophysical Flows, Bound.-Lay. Meteorol., 146, 341-373, doi:10.1007/s10546-0129768-8, 2012.
Zinoviev, A.: Mathematical modeling of hydrological processes in reservoirs and downstream of hydropower stations of Siberian rivers, $\mathrm{PhD}$ thesis, Institute for Water and Ecological Problems, Siberian Branch of RAS, 2014. 